Supporting Information

\title{
Pandonodin: a proteobacterial lasso peptide with an exceptionally long $\mathrm{C}$-terminal tail
}

\author{
Wai Ling Cheung-Lee ${ }^{\dagger}$ Li Cao ${ }^{\dagger}$, and A. James Link ${ }^{\dagger \ddagger \S}$
}

†Department of Chemical and Biological Engineering, Princeton University, Princeton, NJ 08544, United States

‡Department of Chemistry, Princeton University, Princeton, NJ 08544, United States

$\S$ Department of Molecular Biology, Princeton University, Princeton, NJ 08544, United States 


\section{Table of Contents}

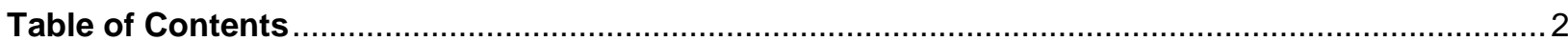

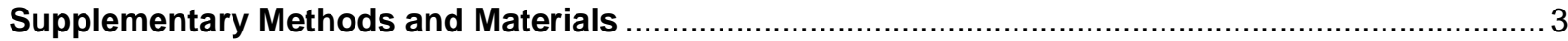

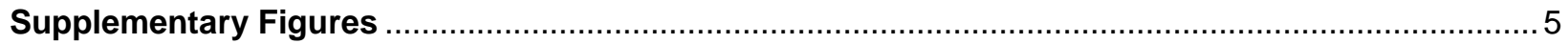

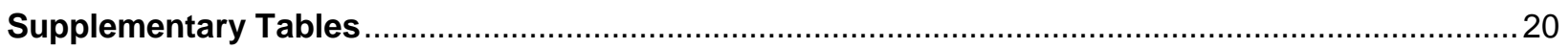




\section{Supplementary Methods and Materials}

\section{Materials and Equipment}

All primers were ordered from Integrated DNA Technologies (IDT). All restriction enzymes and Q5 polymerase were purchased from New England Biolabs (NEB). The sequences of all primers used are provided in Table S4. Pandoraea norimbergensis DSM 11628 was purchased from DSMZ. Genomic DNA was extracted using the Qiagen DNeasy Blood \& Tissue Kit. Strata C8 columns (8B-S005-JCH) were used for solid-phase extraction of culture supernatant. Semi-preparative reverse-phase HPLC was performed using a Zorbax 300SB-C18 $(9.4 \mathrm{~mm} \times 250 \mathrm{~mm}, 5 \mu \mathrm{m})$ column with an Agilent 1200 series instrument. LCMS and LC-MS/MS experiments were done using a Zorbax 300SB-C18 $(2.1 \mathrm{~mm} \times 50 \mathrm{~mm}, 3.5 \mu \mathrm{m})$ column with a 1260 Infinity II system coupled to an Agilent 6530 q-TOF instrument. NMR experiments were done using a Bruker Avance III $800 \mathrm{MHz}$ instrument. DLS was carried out on a Zetasizer Nano-ZS instrument (Malvern).

\section{Cloning}

Pandonodin gene cluster- The panABCD gene cluster was PCR amplified from $P$. norimbergensis DSM 11628 genomic DNA using panABCD For and panABCD Rev primers. The cluster was cloned into pASK75 vector between $X b a l$ and HindlII restriction sites to create pWC100. Wild-type pandonodin peptide was expressed using pWC100. To facilitate the cloning of pandonodin variants, the gene cluster was reformatted into PQE-80, with the panA gene placed under an inducible-T5 promoter and the panBCD genes placed under a constitutively-expressed $m c j B C D$ promoter from the microcin $\mathrm{J} 25$ gene cluster. Briefly, panA was first cloned into pQE-80 using EcoRI and HindllI restriction sites, creating pWC101 with a Kpnl site designed immediately downstream of the EcoRI site for easy swapping of the panA gene. The pan $B C D$ genes were then PCR-amplified from pWC100. The constitutive promoter of $m c j B C D$ from the microcin J25 gene cluster was appended upstream of panBCD in an overlap PCR. This PCR product was then cloned in the forward direction into pWC101 using Nhel restriction site, forming pWC102.

Pandonodin truncation variants- Pandonodin truncation variants were cloned by swapping the panA gene from pWC102 using Kpnl and Hindll restriction enzymes with PCR-generated truncation variants. All clones were sequence-verified. See Table S4 for a full list of primers used for cloning.

Pandonodin fusion proteins- Pandonodin fusion constructs were also cloned by swapping the panA gene from pWC102 with PCR-generated fusion genes.

\section{Expression and purification of pandonodin and pandonodin variants}

Expression of pandonodin and its truncation variants were carried out using Escherichia coli BL21 in M9 media supplemented with $0.00005 \mathrm{wt} \%$ thiamine, 20 amino acids $(0.05 \mathrm{~g} / \mathrm{L}$ of each amino acid), and $100 \mathrm{mg} / \mathrm{L}$ ampicillin. The typical expression scale for variants was a $500 \mathrm{~mL}$ culture in a $2 \mathrm{~L}$ flask. Wild-type pandonodin was expressed and purified from $8 \times 500 \mathrm{~mL}$ cultures.

For expression, an overnight E. coli BL21 culture was grown in LB with $100 \mathrm{mg} / \mathrm{L}$ ampicillin and then subcultured into the supplemented M9 media to a starting $\mathrm{OD}_{600}$ of 0.02 . The $\mathrm{M9}$ cultures were then grown at $37{ }^{\circ} \mathrm{C}, 250 \mathrm{rpm}$ until an $\mathrm{OD}_{600}$ of 0.2 . The cultures were then induced with $200 \mu \mathrm{g} / \mathrm{L}$ anhydrotetracycline (aTc) if they contained a pASK75-based plasmid, or $1 \mathrm{mM}$ of isopropyl-B-Dthiogalactopyranoside (IPTG) if they contained a pQE-80-based plasmid. Expression was carried out at 20 ${ }^{\circ} \mathrm{C}, 250 \mathrm{rpm}$ for 20 hours. Supernatant was harvested by pelleting the cells at $4000 \mathrm{x} \mathrm{g}, 4^{\circ} \mathrm{C}$ for 20 minutes.

Supernatant was then extracted using solid phase extraction with Strata C8 columns. For each 500 $\mathrm{mL}$ expression, a $6 \mathrm{~mL}$ column was first activated with $6 \mathrm{~mL}$ methanol and washed with $12 \mathrm{~mL}$ water. 500 $\mathrm{mL}$ supernatant was pumped through the column with a peristaltic pump. The column was then washed 
against with $12 \mathrm{~mL}$ water, and eluted with $6 \mathrm{~mL}$ methanol. The methanol extract was then dried via rotavap and resuspended in $500 \mu \mathrm{L}$ 1:1 acetonitrile:water. The peptide was then purified from this mixture with reverse-phased HPLC (RP-HPLC). For the large-scale wild-type pandonodin expression (4 L), the dried extract was resuspended in $3 \mathrm{~mL} 1: 2$ acetonitrile:water.

Typically for RP-HPLC purification, 60-80 $\mu \mathrm{L}$ of sample was injected onto the semi-preparative column and separated using gradient elution. The mobile phase A consisted of water with $0.1 \%$ trifluoroacetic acid and phase B consisted of acetonitrile with $0.1 \%$ trifluoroacetic acid. The gradient program used was as follows: $10 \%$ B from 0-1 minute, linear gradient from 10-50\% B from 1-20 minutes, linear gradient from 50-90\% B from 20-25 minutes, and isocratic elution at 90\% B from 25-27 minutes.

\section{Expression and purification of pandonodin fusion proteins}

The PanA-thrombin_site-A1-His6, PanA- thrombin_site-sfGFP-His6, PanA $\Delta$ C12-A1-His6, and PanA $\triangle C 12-A 1_{12}$ constructs were transformed into E. coli BL21. Small overnight cultures were grown in LB with $100 \mathrm{mg} / \mathrm{L}$ ampicillin. The PanA $\Delta C 12-\mathrm{A}_{12}$ was expressed in $500 \mathrm{~mL}$ M9 culture, following the same expression and purification conditions as for the wild-type pandonodin and truncation variants (see above). In addition to extracting the supernatant for peptide, the cell pellet was also extracted for potential peptide(s) related to the expression. Briefly, the cell pellet was first washed with $10 \mathrm{~mL}$ PBS and then re-pelleted. The cells were then lysed and extracted with $10 \mathrm{~mL}$ methanol (resuspended with methanol, added $\sim 10$ glass beads, vortexed for 10 minutes). The debris was then removed via centrifugation and the methanol extract was processed as in the above section for the supernatant methanol extracts, except that the dried extract was resuspended in $100 \mu \mathrm{L}$ 1:1 acetonitrile:water.

The three constructs with His-tags were expressed in $500 \mathrm{~mL}$ LB with ampicillin. The overnight cultures were diluted 1:100, and grew until an $\mathrm{OD}_{600}$ of 0.5 . They were then induced with $1 \mathrm{mM}$ IPTG and expressed at $20{ }^{\circ} \mathrm{C}$ for 20 hours. Cells were then harvested by centrifugation at $4000 \times \mathrm{g}, 4{ }^{\circ} \mathrm{C}$, for 20 minutes. Native affinity purification based on the Qiagen protocol was then performed to purify the Histagged proteins. Cells were resuspended in $10 \mathrm{~mL}$ lysis buffer with $10 \mathrm{mM}$ imidazole and frozen at $-80{ }^{\circ} \mathrm{C}$ for 30 minutes, and then thawed in an ice-water bath. Lysozyme $(1 \mathrm{mg} / \mathrm{mL})$ was added to the cells, which were then incubated on ice for 30 minutes. Next, the cells were sonicated in an ice-water bath with $10 \times 15$ sec pulses. The lysate was then centrifuged at $8000 \times \mathrm{g}, 4^{\circ} \mathrm{C}$ for 15 minutes. The lysate was then transferred to a new tube, and centrifugation was repeated to further remove solid debris. Next $2 \mathrm{~mL}$ of $50 \% \mathrm{Ni}-\mathrm{NTA}$ resin (Qiagen) was added, and incubated with the lysate on a rotary shaker at $4{ }^{\circ} \mathrm{C}$ for $1-2$ hours. The resin-lysate mixture was then transferred to a column, and washed sequentially with $10 \mathrm{~mL} 10$ $\mathrm{mM}$ imidazole, $10 \mathrm{~mL} 10 \mathrm{mM}$ imidazole, and $5 \mathrm{~mL} 50 \mathrm{mM}$ imidazole. Finally, the protein was eluted with 5 x $1 \mathrm{~mL} 250 \mathrm{mM}$ imidazole elution buffer. 


\section{Supplementary Figures}

A

Leader sequence of precursor $A$ Core sequence of precursor $A$

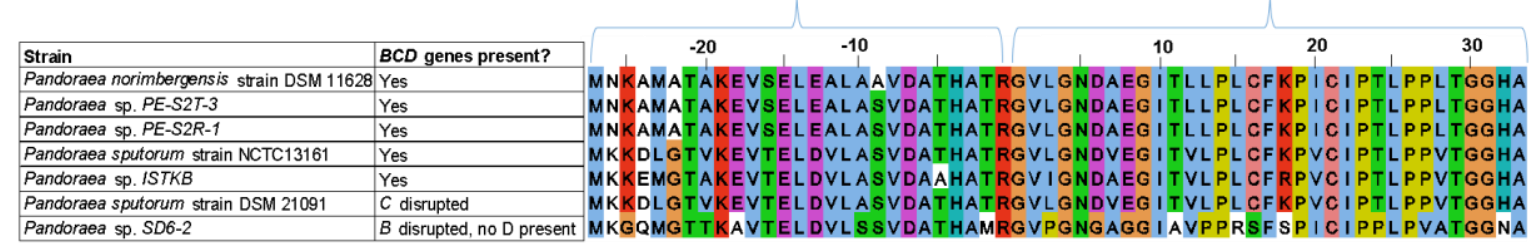

B

\begin{tabular}{|c|c|c|c|c|c|c|}
\hline \multirow{2}{*}{\begin{tabular}{|l|} 
Strain \\
Pandoraea norimbergensis strain DSM 11628 \\
\end{tabular}} & \multicolumn{2}{|c|}{ NCBI Reference Sequence A locus } & \multirow{2}{*}{\begin{tabular}{|l|} 
Start/Stop of A \\
$1,649,034.1,649,216$ \\
\end{tabular}} & \multicolumn{3}{|c|}{ Direction Genome Assembly $B C D$ genes present? } \\
\hline & NZ_CP013480.3 & WP_ 058377877 & & forward & Whole & Yes \\
\hline Pandoraea sp. PE-S2T-3 & NZ NGUQ01000006.1 & WP 087686732 & $35,386.35,568$ & reverse & contig00006 & Yes \\
\hline Pandoraea sp. PE-S2R-1 & NZ_NGUR01000007.1 & WP_087686732 & $270,282.270,464$ & forward & contig00007 & Yes \\
\hline Pandoraea sputorum strain NCTC13161 & NZ_LT9O & WP_039397102 & $1,572,372.1,572,554$ & forward & Whole & Yes \\
\hline Pandoraea sp. ISTKB & NZ_MAOS01000083 & WP_069344820 & $170,288 . .170,470$ & forward & scaffold7 & Yes \\
\hline Pandoraea sputorum strain DSM 21091 & NZ_CP010431.2 & WP_039397102 & $1,572,861 . .1,573,043$ & forward & Whole & C disrupted \\
\hline Pandoraea sp. SD6-2 & NZ_KB944444.1 & WP 010805942 & $163,291 . .163,473$ & forward & scaffold29 & B disrupted, no D present \\
\hline
\end{tabular}

Figure S1. Pandonodin-like gene clusters in Pandoraea genus. (A) Table containing BLAST search results with strain information, analysis of whether the gene cluster is intact, and an alignment of the predicted precursor sequence from each gene cluster. (B) Detailed information for the location of the pandonodin-like gene clusters. 

A
10
20
30

GVIGNDAEGITLIPLCFKPI IPTIPPITGGHA

$\overline{\mathrm{y}_{25}} \overline{\mathrm{y}_{24} \overline{\mathrm{y}}_{23}} \overline{\mathrm{y}_{22}} \quad \overline{\mathrm{y}_{20}}$

$\begin{array}{lllll}\bar{y}_{12} \bar{y}_{11} & \overline{y_{9}} \bar{y}_{8} \bar{y}_{7} & \overline{y_{4}} & \overline{y_{2}}\end{array}$
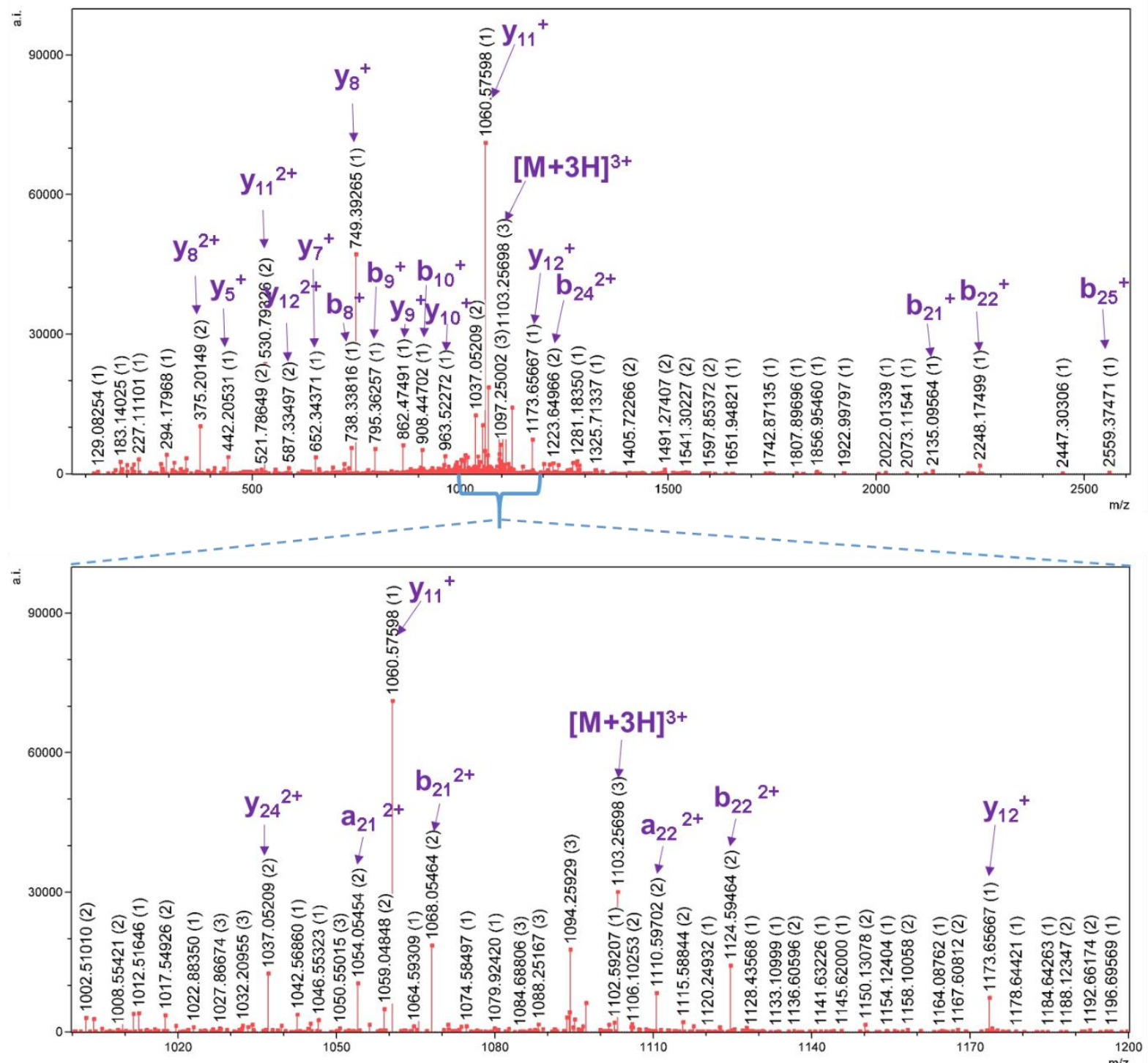

Figure S2 continued on following page. 
B
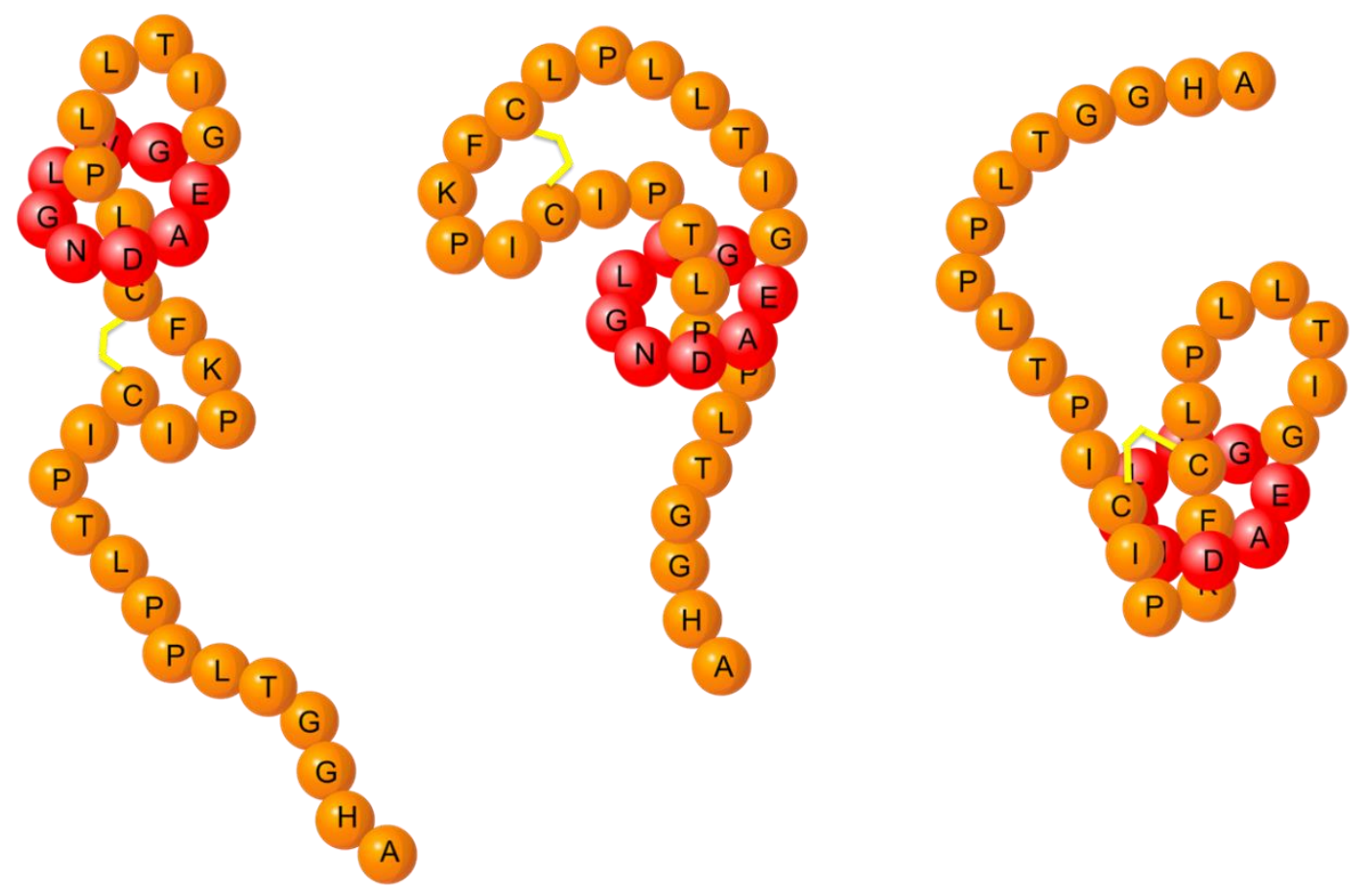

Figure S2. MS/MS analysis of pandonodin. (A) Sample MS/MS spectrum of pandonodin. Parent ion $[\mathrm{M}+3 \mathrm{H}]^{3+}$ is indicated in the spectrum along with the major $b$ and $y$ ion species that were observed. (B) Cartoons of possible linkage topologies involving a disulfide bond between the two Cys residues. The MS/MS pattern observed in $(A)$ is consistent with the two leftmost topologies.

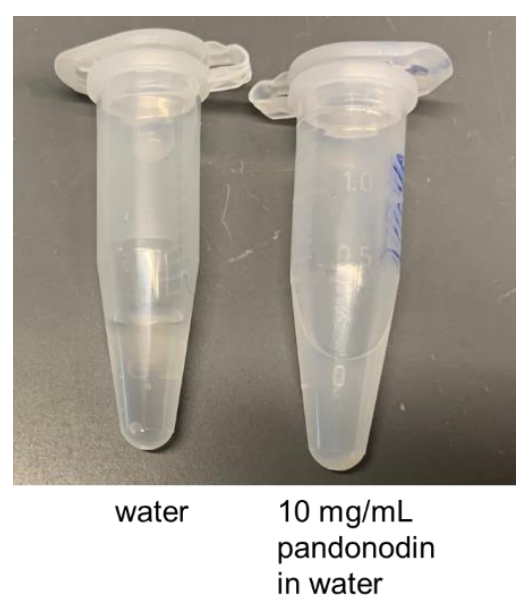

Figure S3. Pandonodin solubility in water. Picture of $300 \mu \mathrm{L}$ of pandonodin resuspended in water, taken next to pure water for comparison purposes. 


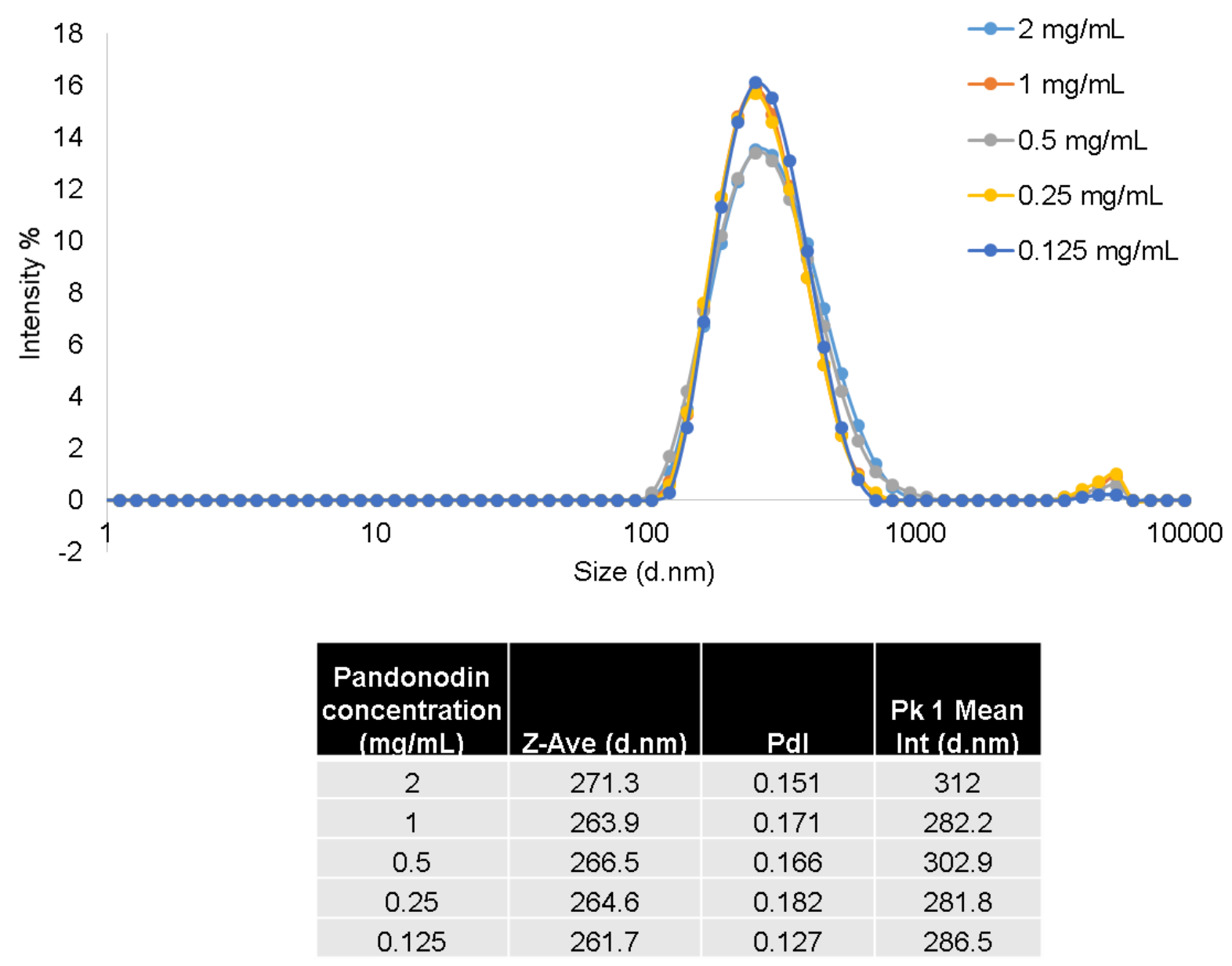

Figure S4. Dynamic light scattering measurements of pandonodin in water. 
A

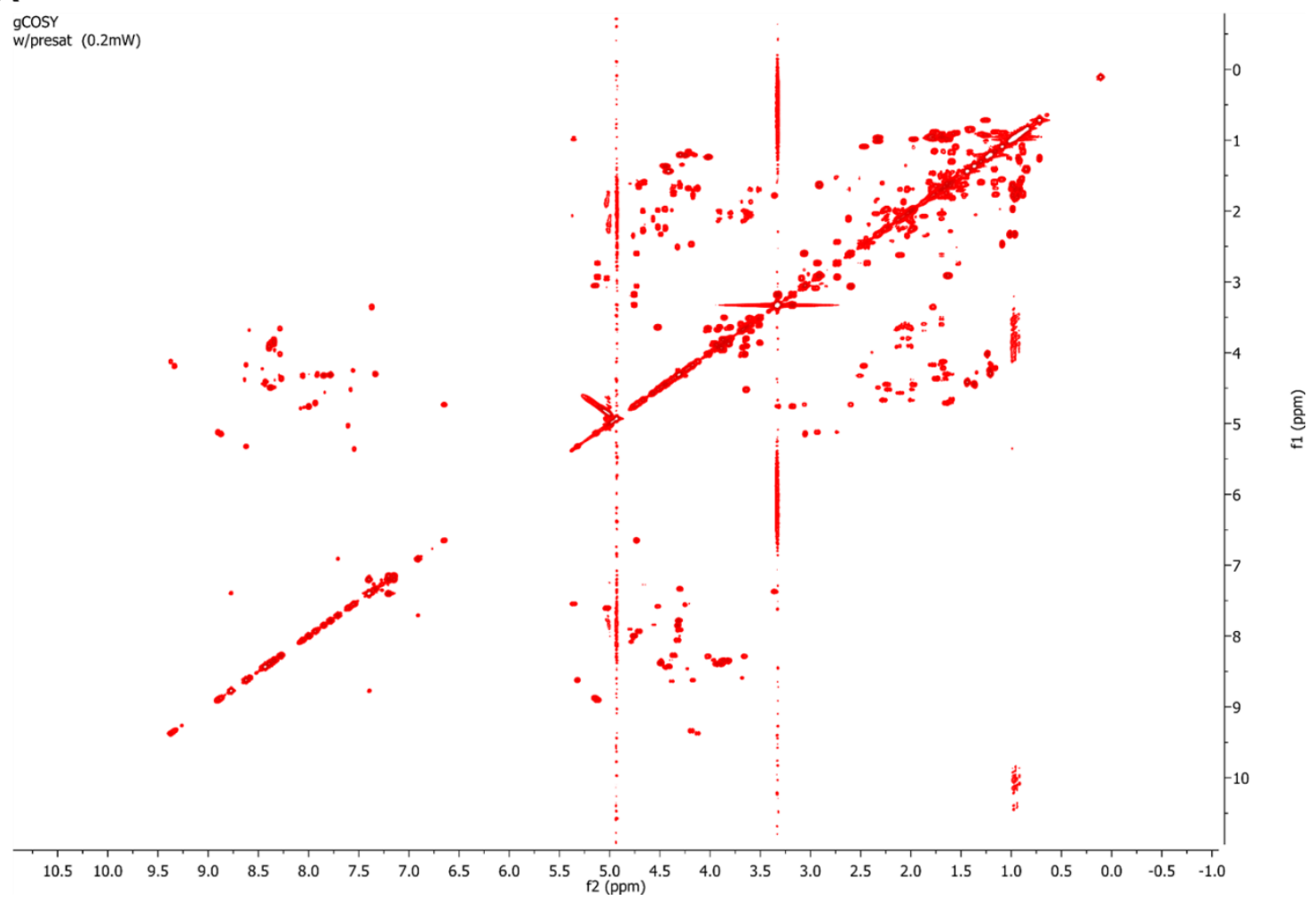

\section{B}

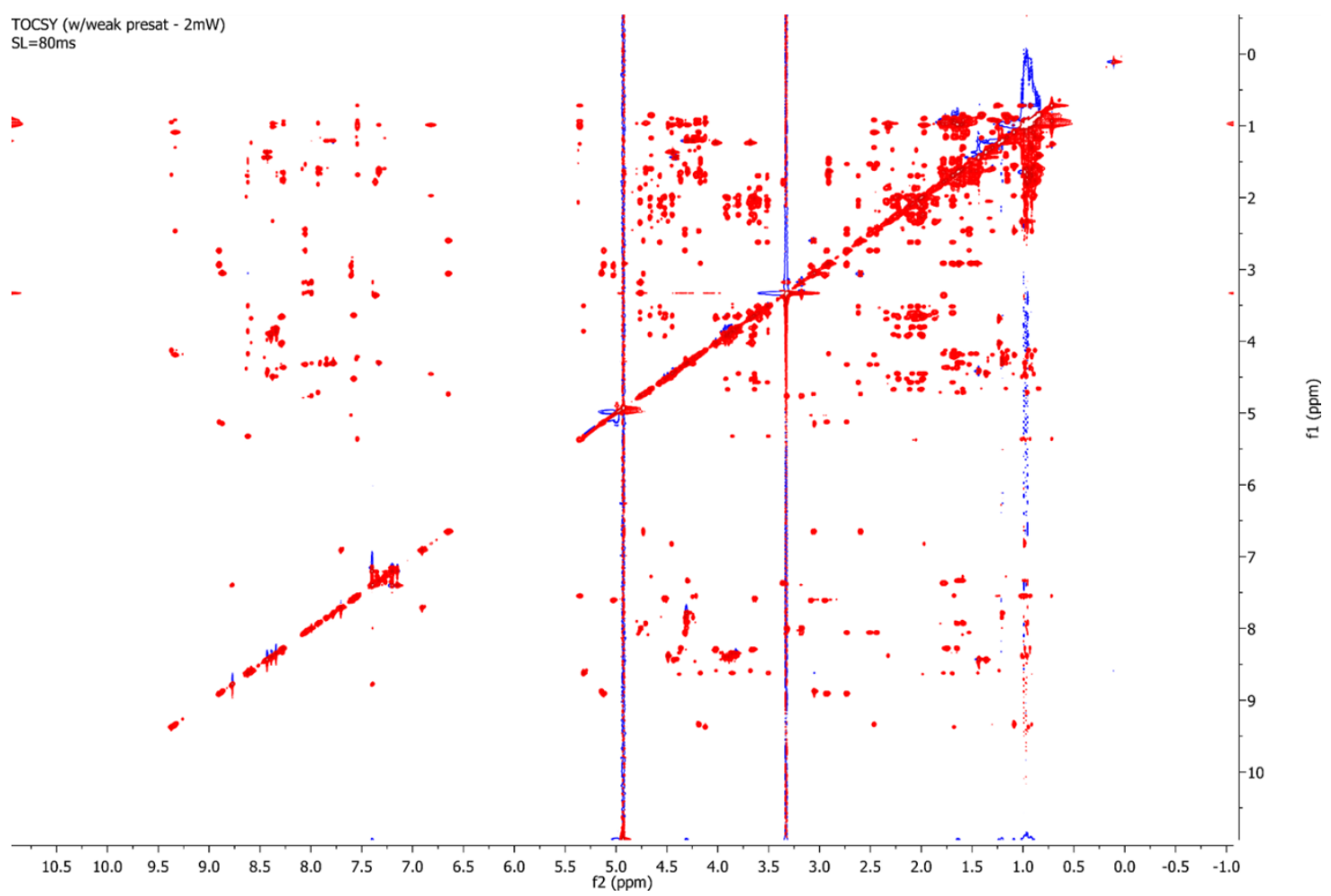

Figure S5 continued on following page. 
C

NOESY (w/presat - $0.5 \mathrm{~mW}$ )

$\mathrm{mix}=500 \mathrm{~ms}$
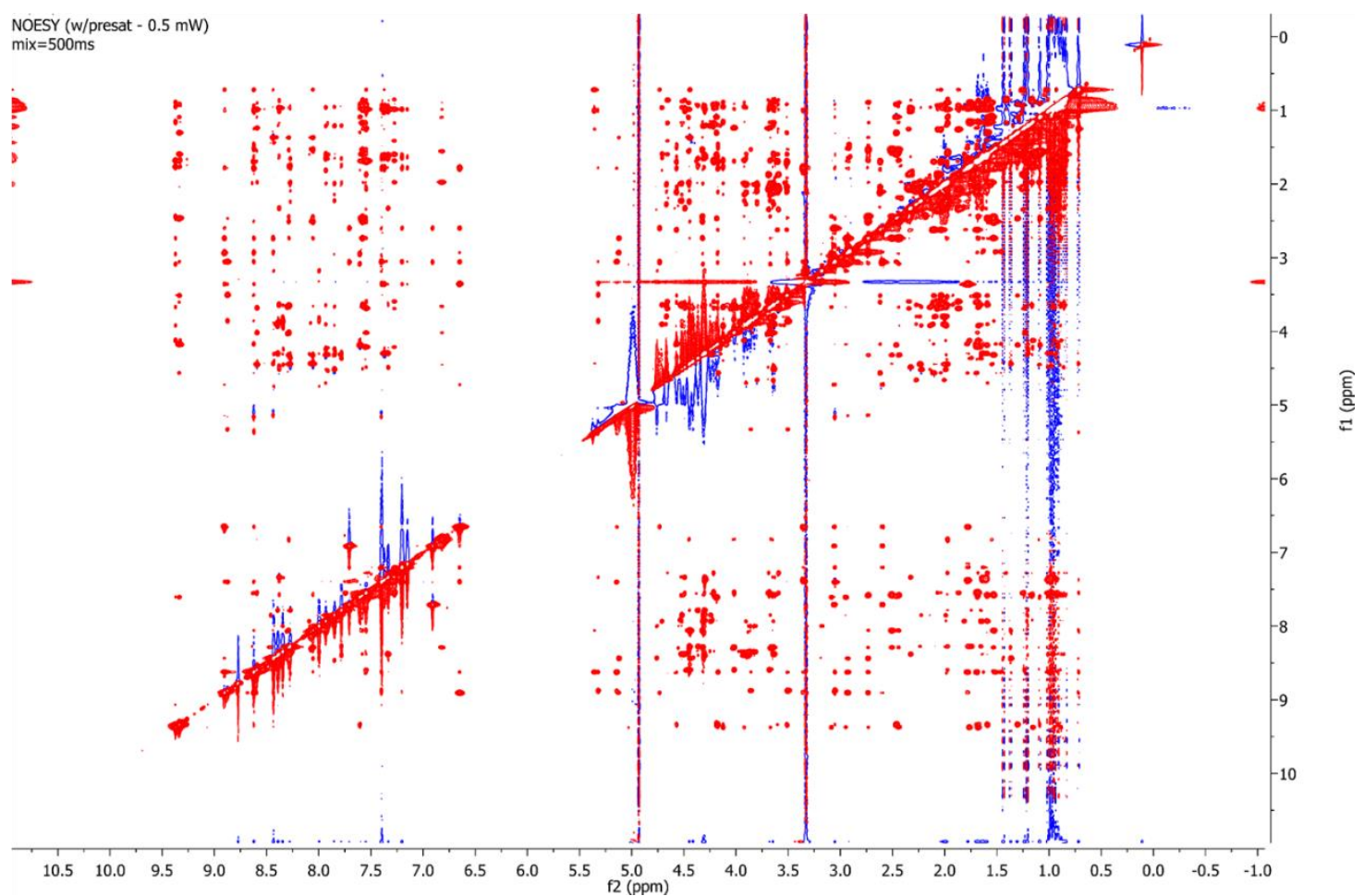

D

C,H-HSQC -- gradient selection, with DEPT editing w/adiabatic $13 \mathrm{C}$ inversion pulses and decoupling
$50 \%$ NUS

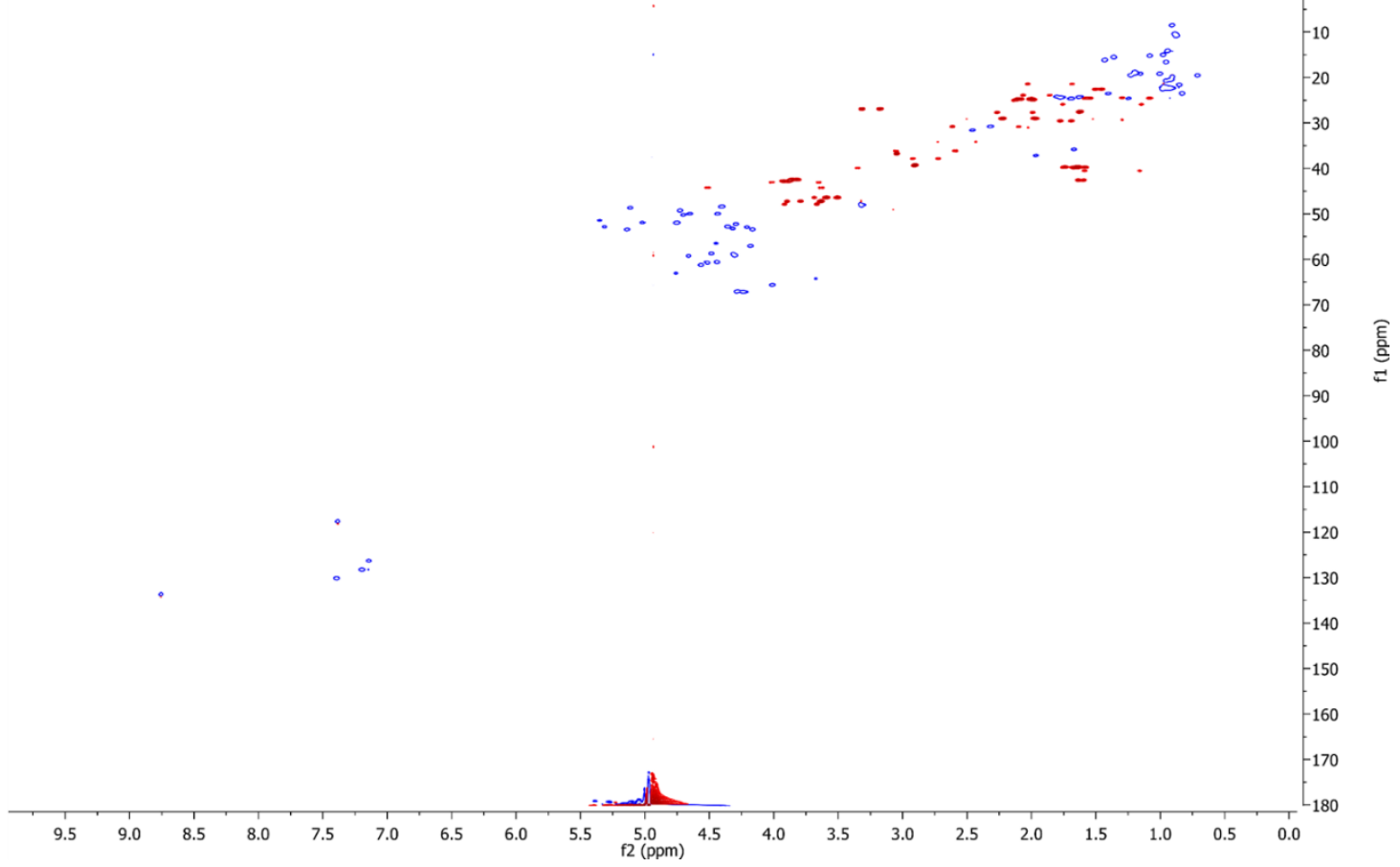

Figure S5. 2D NMR spectra of full-length pandonodin. (A) gCOSY (B) TOCSY (C) NOESY (D) HSQC 
A

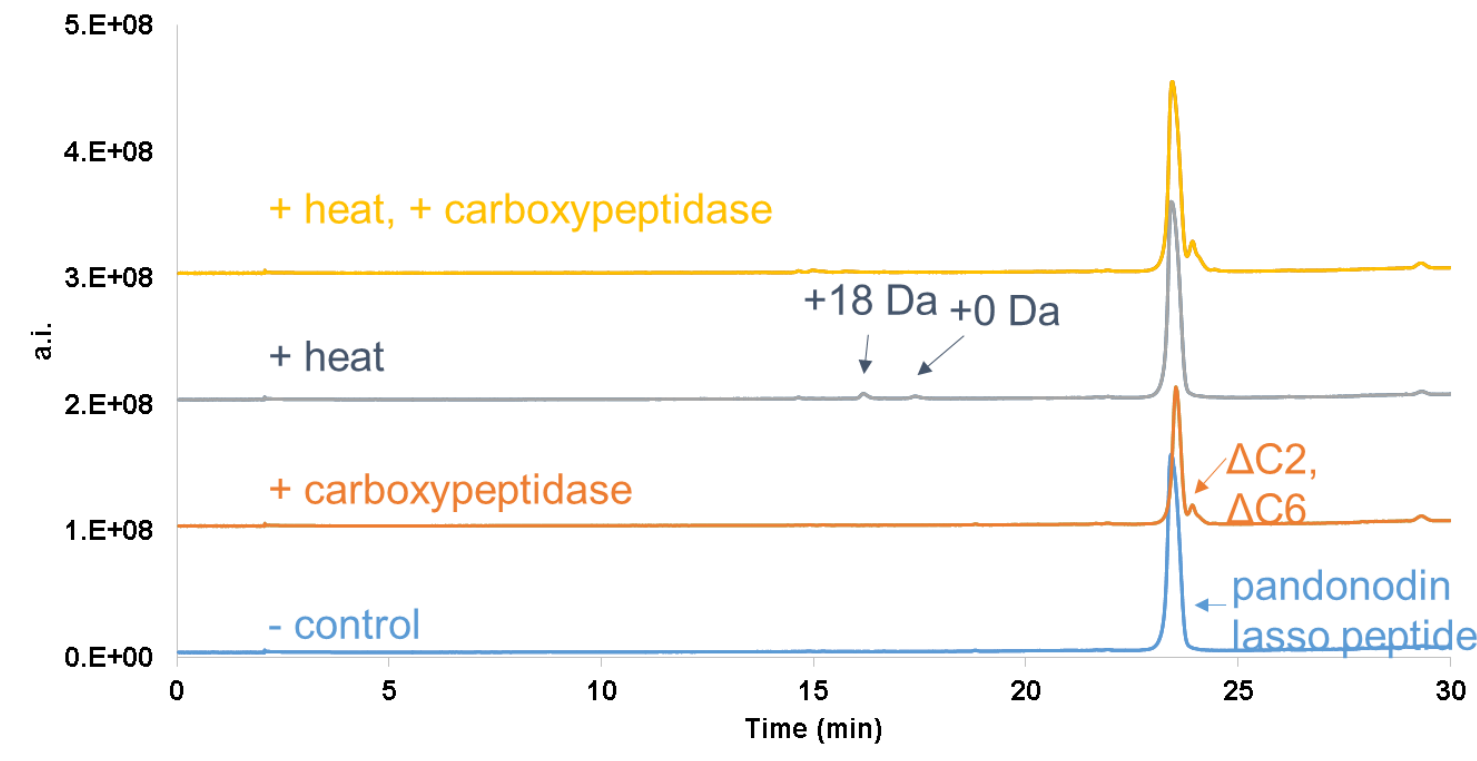

B

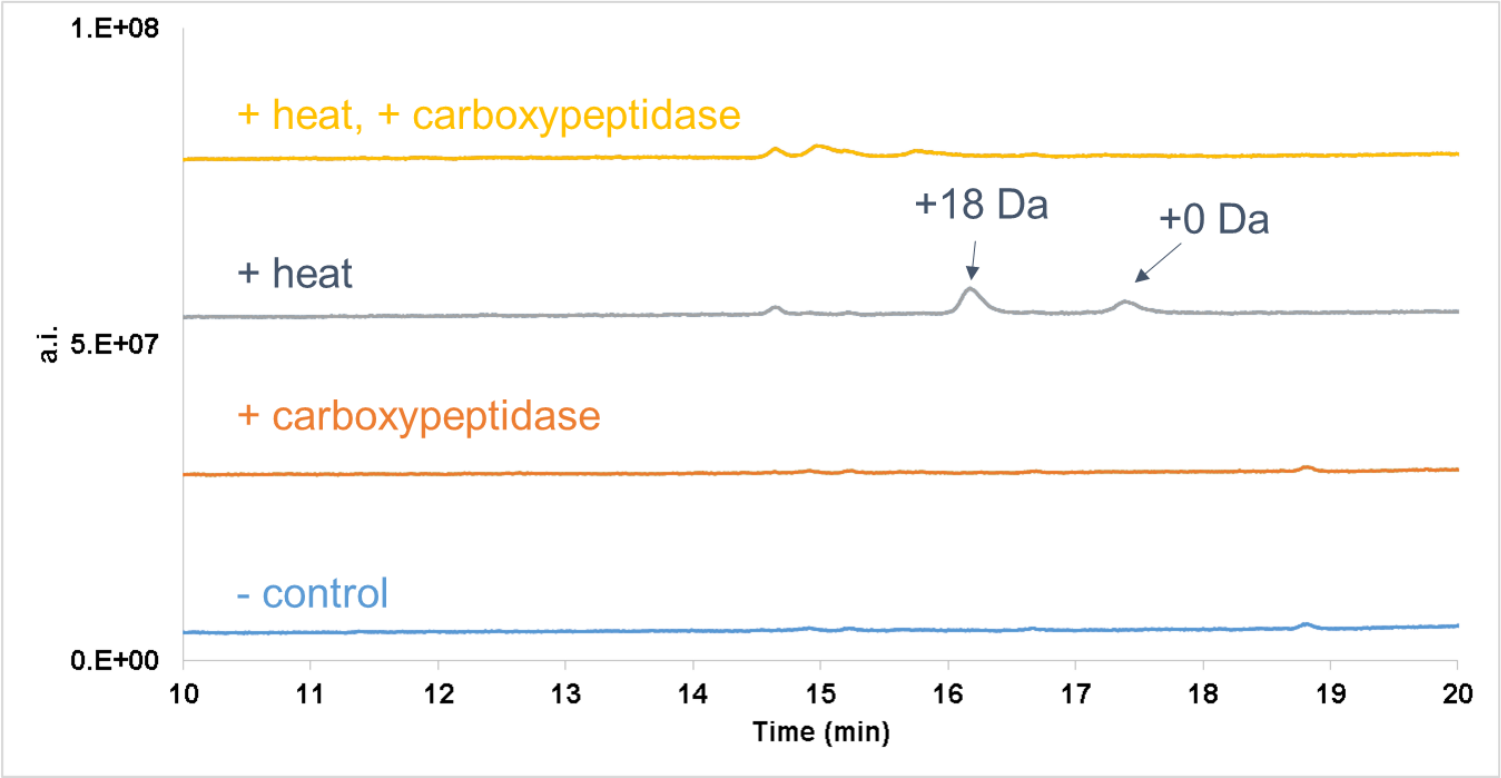

Figure S6. LC-MS analysis of pandonodin thermal stability. (A) TIC chromatogram of pandonodin, pandonodin treated with carboxypeptidase, pandonodin heat-treated at $95{ }^{\circ} \mathrm{C}$ for 2 hour, and pandonodin heat-treated then carboxypeptidase-treated. Pandonodin remained mostly intact after 2 hours of heating, with only two minor degradation species, as indicated by the labeled peaks that correspond to +0 and +18 Da mass changes. The +0 species is a putatively unthreaded lasso peptide whereas the +18 species likely corresponds to cleavage after Asp. Both of these peaks disappear upon carboxypeptidase treatment. (B) Zoom-in of (A) 

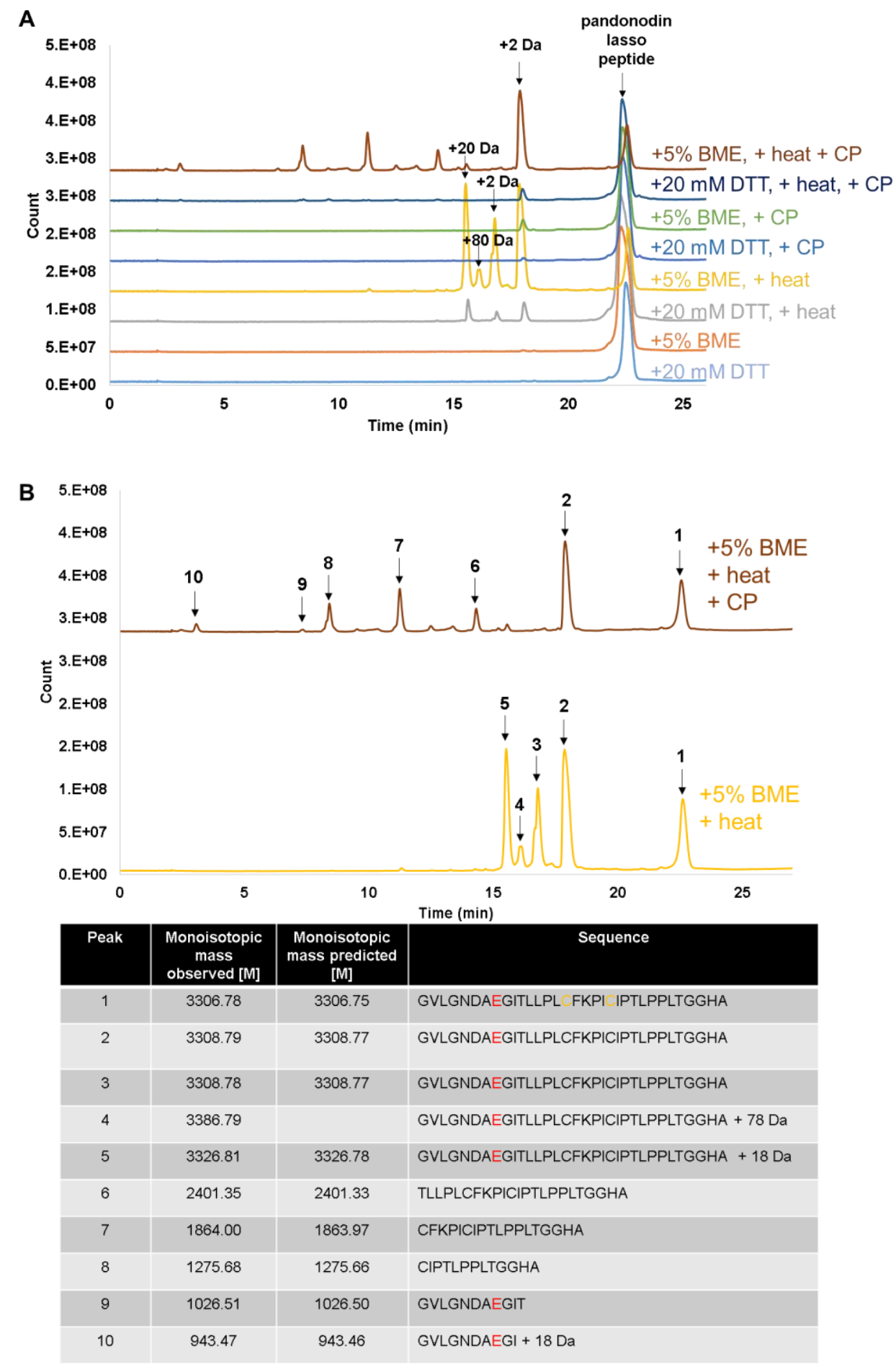

Figure S7. LC-MS analysis of pandonodin thermal stability under reducing conditions. (A) TIC chromatograms of pandonodin treated under indicated conditions. BME $=\beta$ - mercaptoethanol, $\mathrm{DTT}=$ dithiothreitol, heat $=2$ hours at $95^{\circ} \mathrm{C}, \mathrm{CP}=$ carboxypeptidase digestion. Peaks corresponding to the reduced mass $(+2 \mathrm{Da})$, and hydrolyzed and reduced mass $(+20 \mathrm{Da})$ are indicated on the chromatogram. (B) Further analysis of the samples containing BME. Peaks and their corresponding masses are provided in the table. The red " $E$ " indicates observed mass is consistent with the presence of the isopeptide bond, and yellow " $C$ " indicates disulfide bonded cysteine. 
A

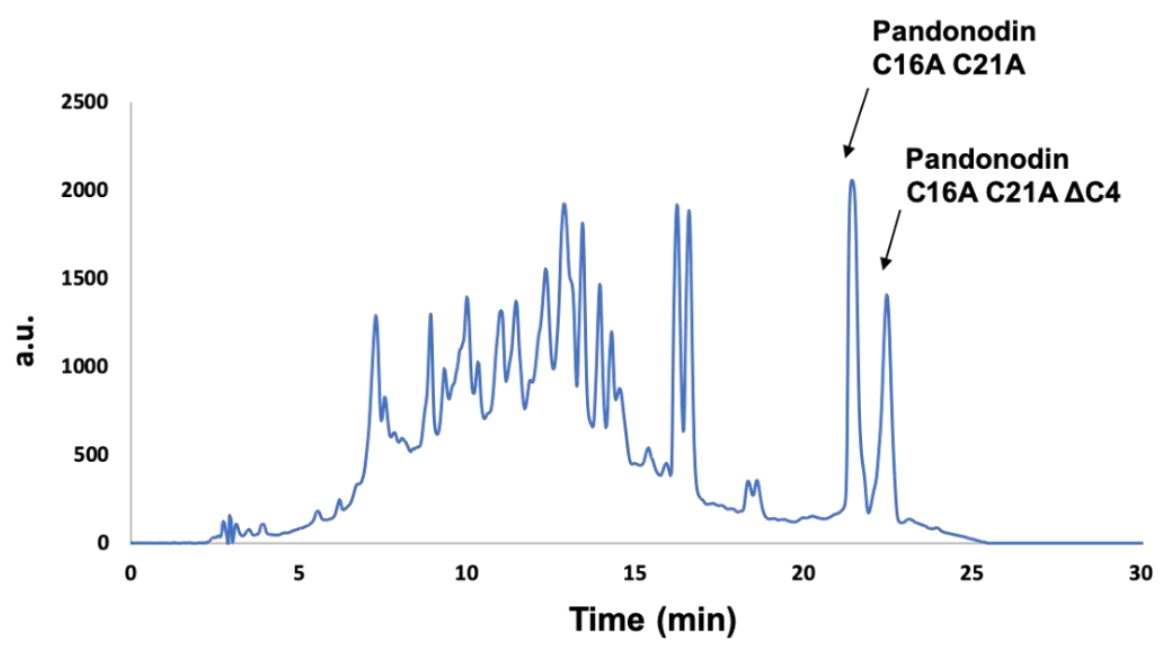

B

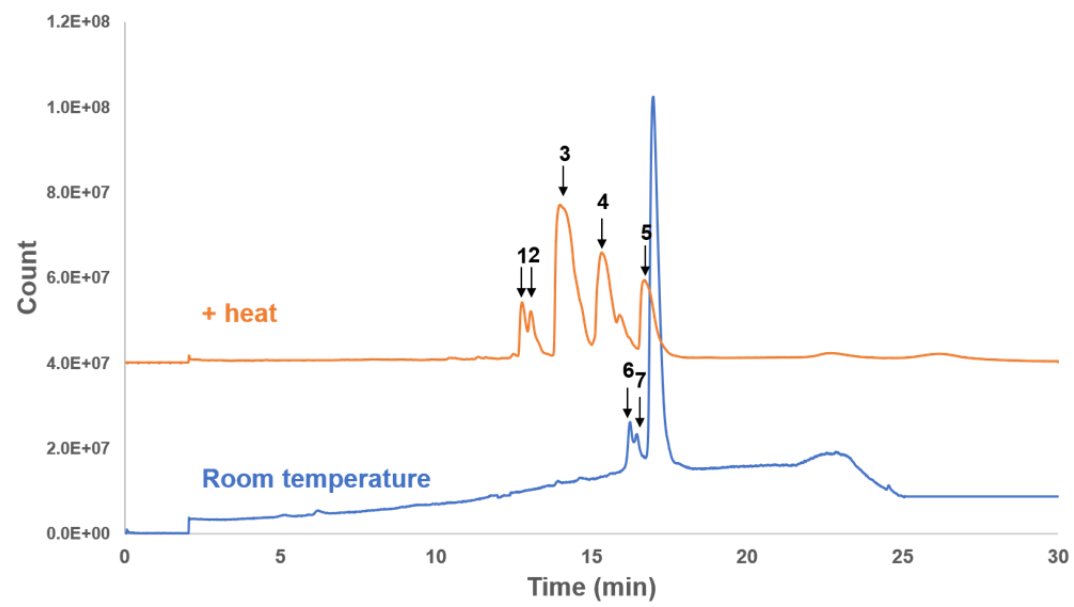

\begin{tabular}{|c|c|c|c|}
\hline Peak & $\begin{array}{c}\text { Monoisotopic } \\
\text { mass (M) } \\
\text { observed }\end{array}$ & $\begin{array}{c}\text { Monoisotopic } \\
\text { mass (M) } \\
\text { predicted }\end{array}$ & Sequence \\
\hline 1 & 2108.20 & 2108.20 & GVLGNDAEGITLLPLAFKPIA +18 Da \\
\hline 2 & 2037.16 & 2037.16 & GVLGNDAEGITLLPLAFKPI +18 Da \\
\hline 3 & 3262.85 & 3262.84 & GVLGNDAEGITLLPLAFKPIAIPTLPPLTGGHA +18 Da \\
\hline 4 & 3244.84 & 3244.82 & $\begin{array}{r}\text { GVLGNDAEGITLLPLAFKPIAIPTLPPLTGGHA } \\
\text { (unthreaded) }\end{array}$ \\
\hline 5 & 3244.84 & 3244.82 & GVLGNDAEGITLPLAFKPIAIPTLPPLTGGHA \\
\hline 6 & 2090.18 & 2090.18 & (threaded) \\
\hline 7 & 2019.15 & 2019.15 & GVLGNDAEGITLLPLAFKPIA \\
\hline & & & GVLGNDAEGITLLPLAFKPI \\
\hline
\end{tabular}

Figure S8: Characterization of pandonodin C16A C21A (pandonodin AA for brevity). A: HPLC trace of culture supernatant containing pandonodin AA. A product corresponding to removal of 4 aa from the $C$-terminus of pandonodin AA $(\triangle C 4)$ is also observed in large quantities. B: LC-MS analysis of pandonodin AA heating at $95^{\circ} \mathrm{C}$ for $2 \mathrm{~h}$. The HPLC peak corresponding to full-length pandonodin AA has small amounts of $\Delta \mathrm{C} 12$ and $\Delta \mathrm{C} 13$ species. Pandonodin AA more readily unthreads than wild-type pandonodin and is more susceptible to thermally induced cleavage after Asp in the ring (see also Figure $\mathrm{S} 11$ below). 
A

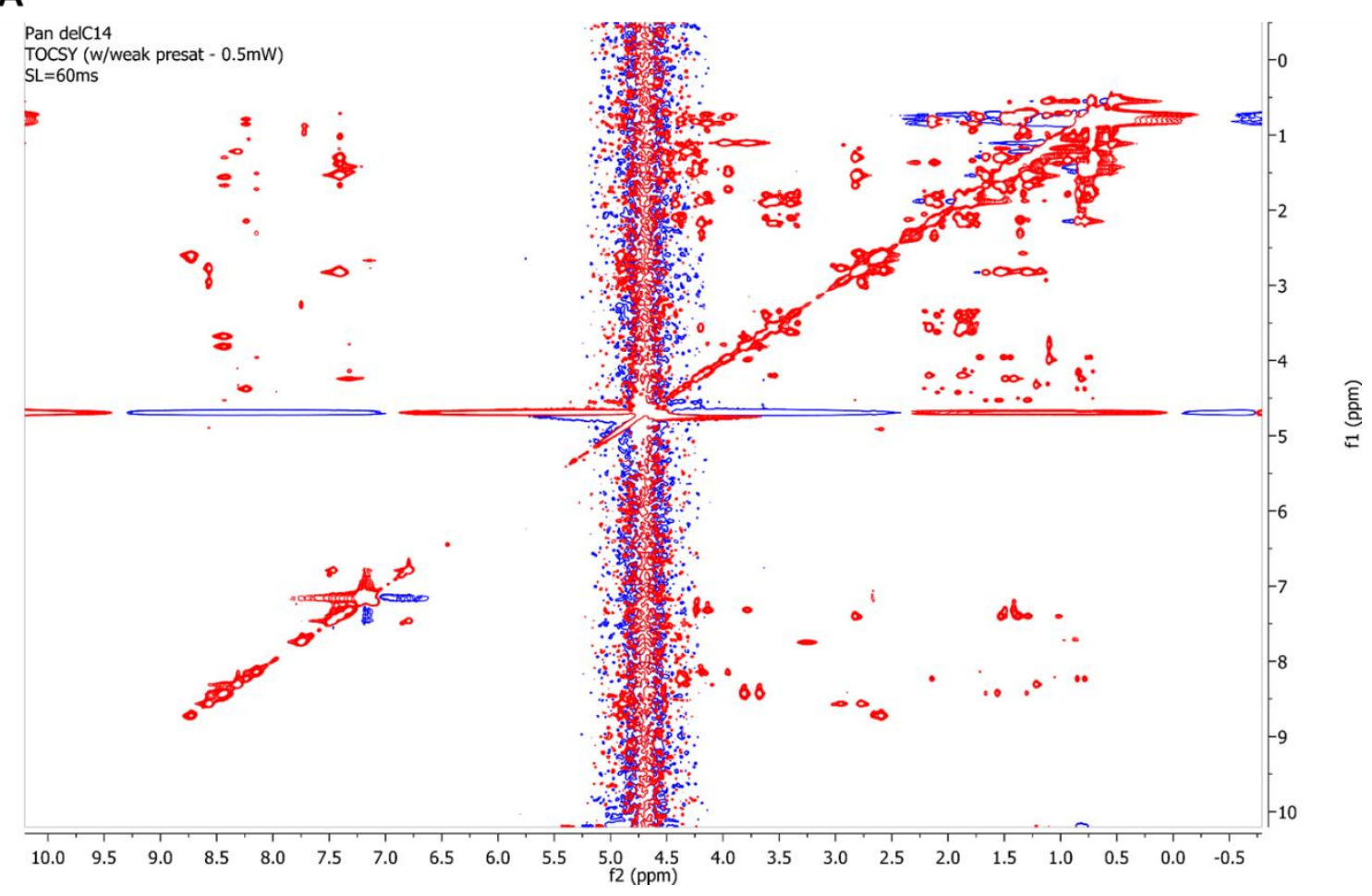

B

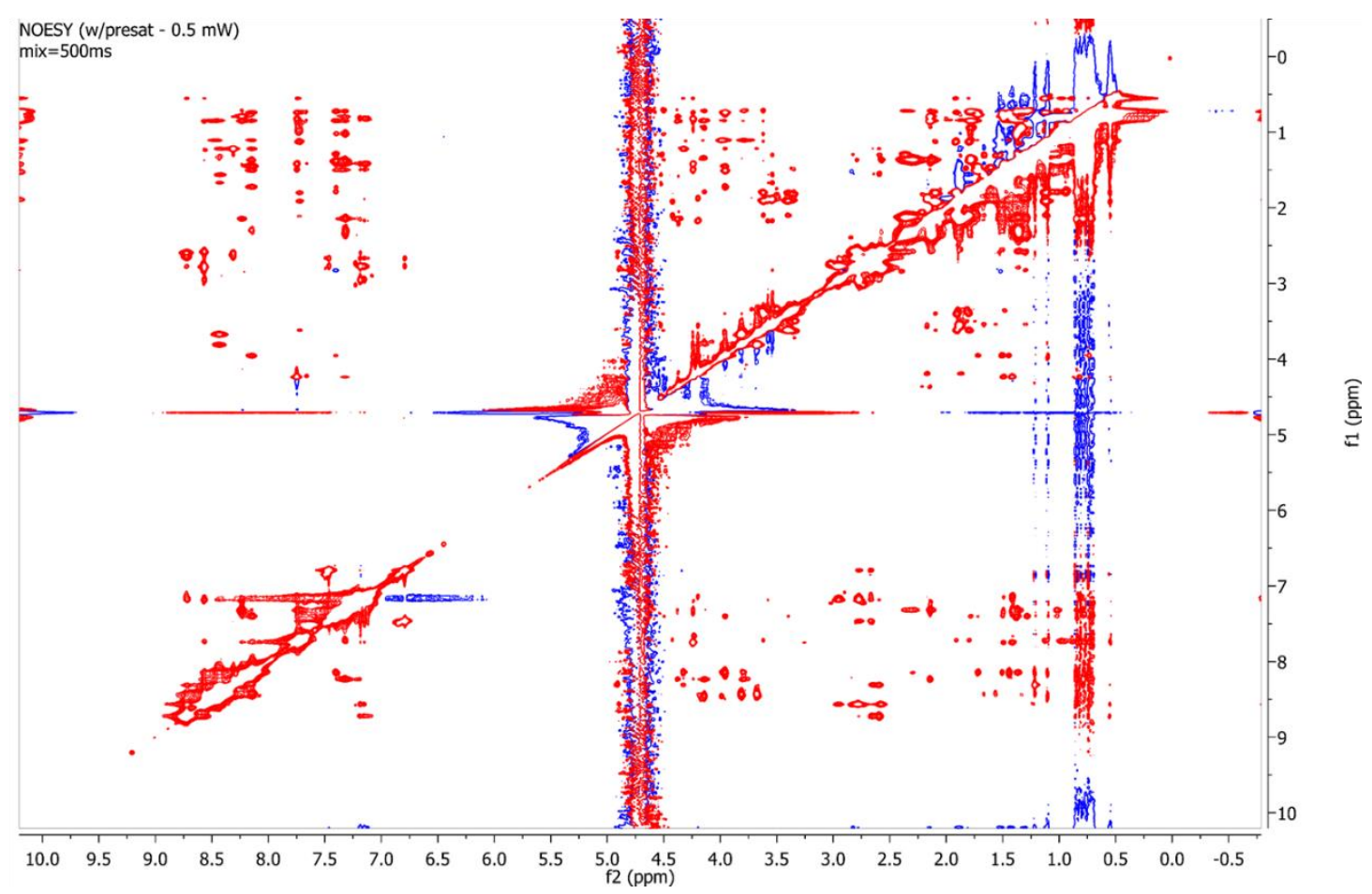

Figure S9. 2D NMR spectra of pandonodin $\triangle C 14$. (A) TOCSY (B) NOESY 
A

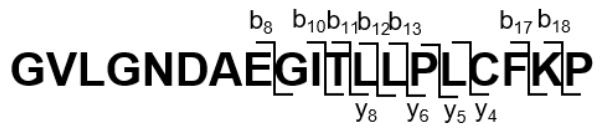

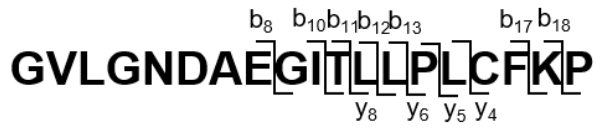
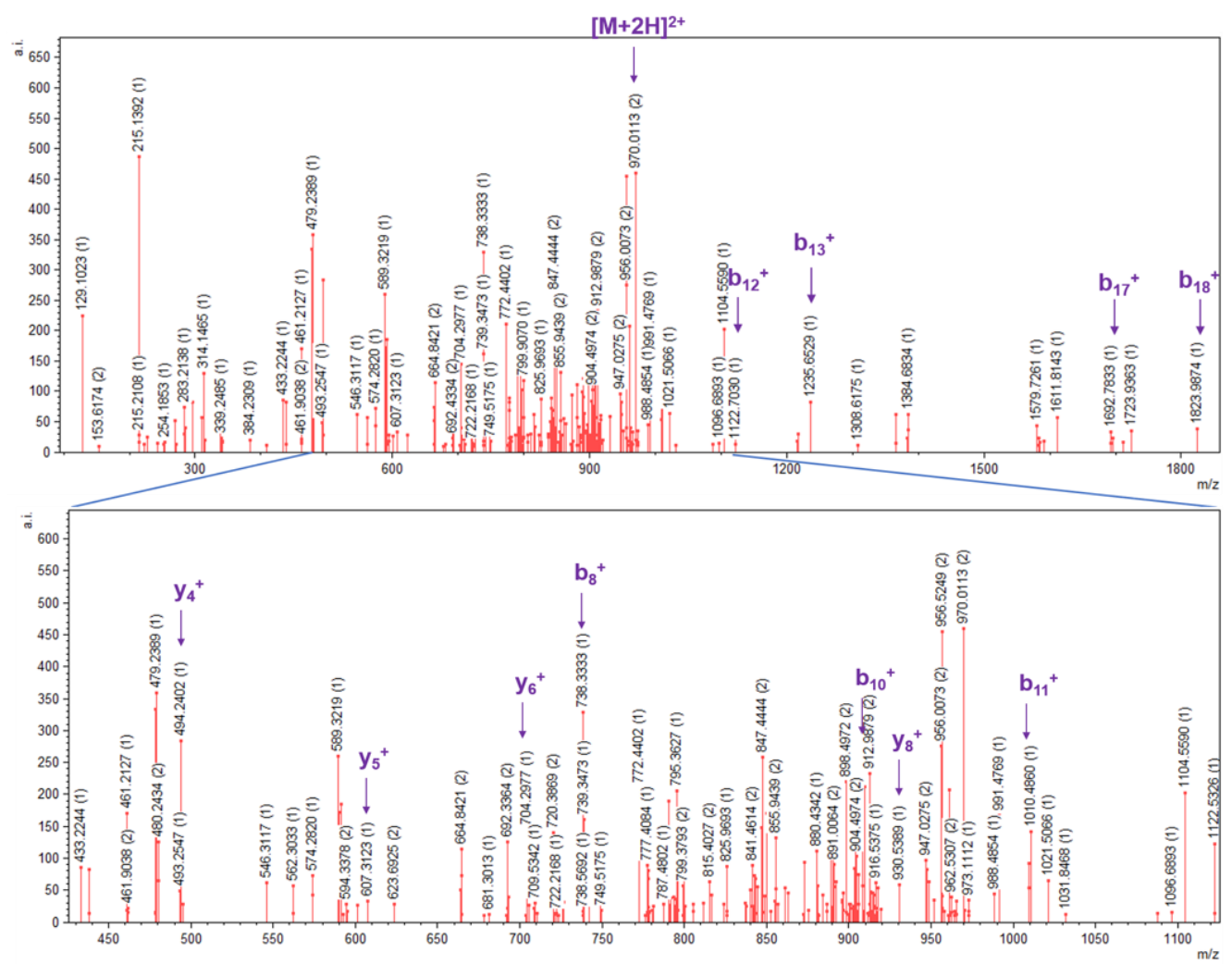

B

$b_{8} \quad b_{10} \quad b_{12} b_{13}$
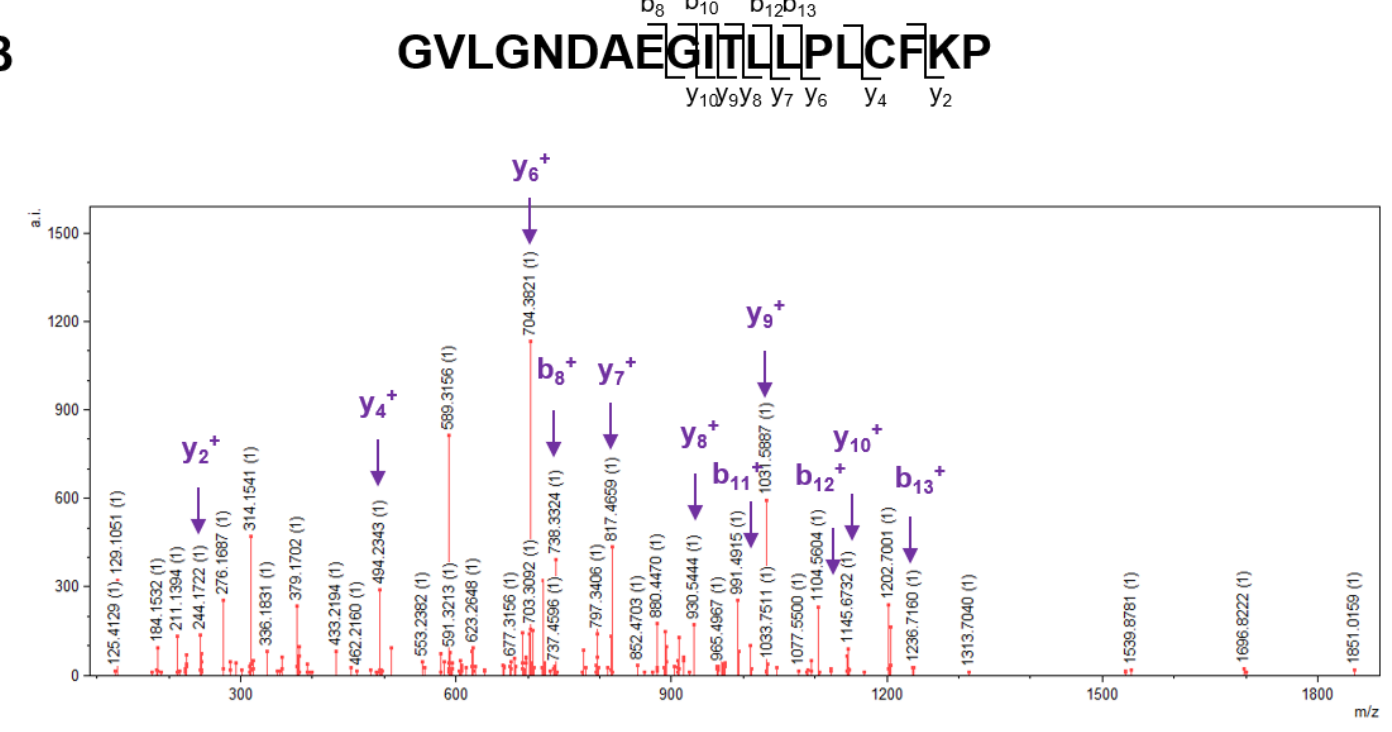

Figure S10: MS/MS spectra of threaded $(A)$ and unthreaded $(B)$ pandonodin $\Delta C 14$. For the threaded peptide, a major peak is the parent ion, showing that this species is difficult to fragment. For the unthreaded peptide, the parent ion is completely fragmented. In both cases, fragmentation occurs C-terminal to the isopeptide-bonded ring. 

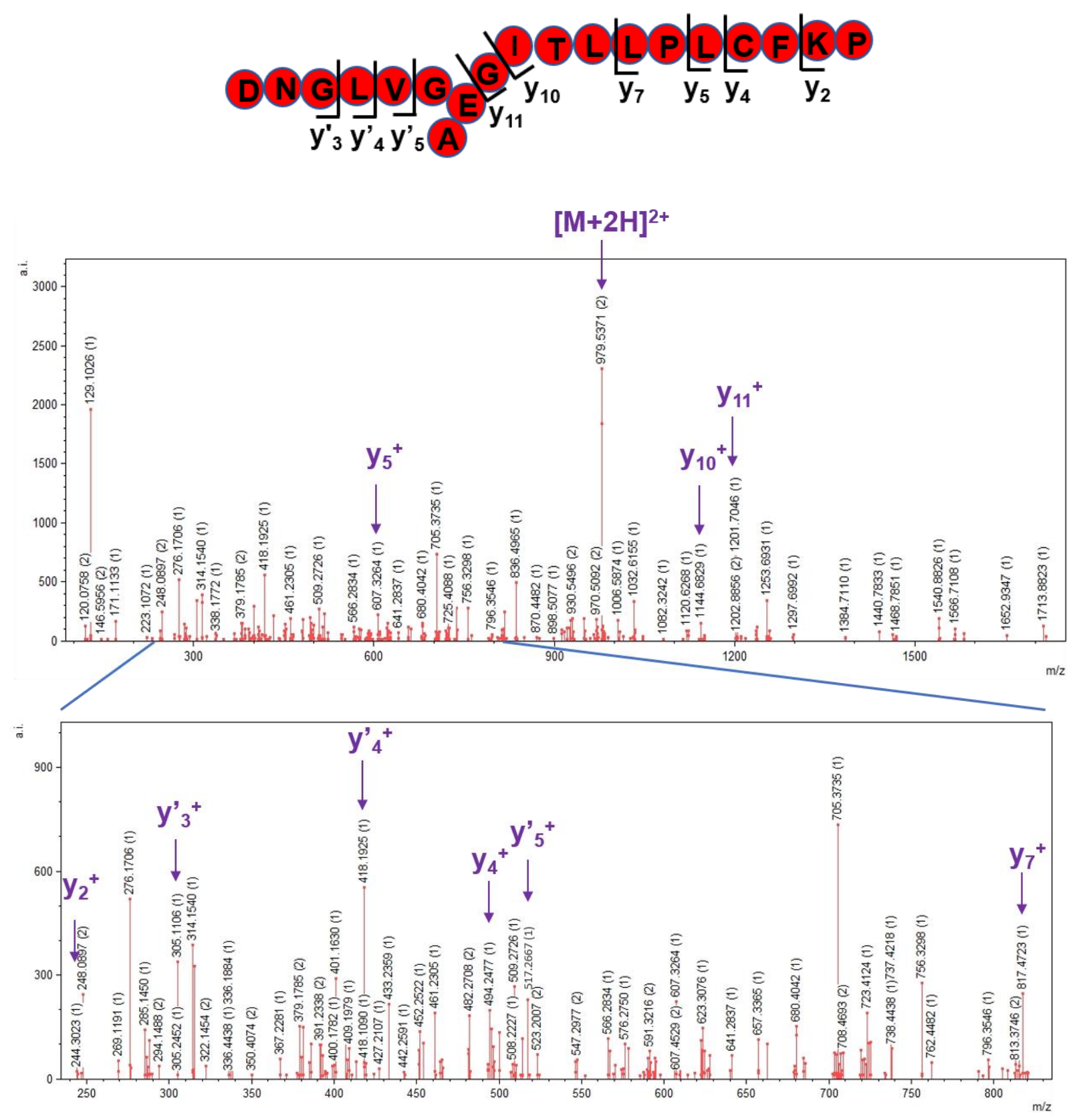

Figure S11: MS/MS on ring-cleaved, branched pandonodin $\Delta \mathrm{C} 14$. The result indicates the hydrolysis occurs C-terminal to the Asp in the ring. 
A PanA: MNKAMATAKEVSELEALAAVDATHATRGVLGNDAEGITLLPLCFKPICIPTLPPLTGGHA

A1: MASGDLENEVAQLEREVRSLEDEAAELEQKVSRLKNEIEDLKAEIGDLNNTSGIRRPAAKLN MSKGEELFTGVPILVELDGDVNGHKFSVRGEGEGDATNGKLTLKFICTTGKLPVPWPTLV IFFP: TLTYGVQCFSRYPDHMKRHDFFKSAMPEGYVQERTISFKDDGTYKTRAEVKFEGDTLVN RIELKGIDFKEDGNILGHKLEYNFNSHNVYITADKQKNGIKANFKIRHNVEDGSVQLADHYQ QNTPIGDGPVLLPDNHYLSTQSVLSKDPNEKRDHMVLLEFVTAAGITHGMDELYK

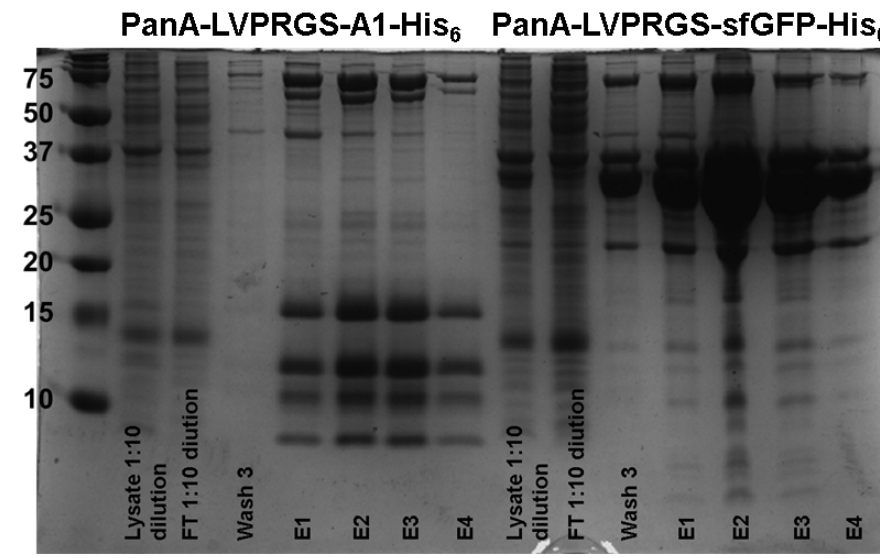

B

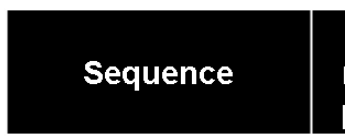

Average

Average

mass [M] mass [M] predicted observed

PanA-LVPRGS-A1$\mathrm{His}_{6}+$ disulfide bond 14461.53

Volume

GVLGNDAEGITLLPL CFKPICIPTLPPLTGG HA-LVPRGS-A1-His

+ isopeptide bond + disulfide bond

\section{$11631.17 \quad 11631.14 \quad 56,578,544$} disterich

8340.21

8340.12

$4,215,545$

C

\begin{tabular}{|c|c|c|c|}
\hline Sequence & $\begin{array}{c}\text { Average } \\
\text { mass [M] } \\
\text { predicted }\end{array}$ & $\begin{array}{c}\text { Average } \\
\text { mass [M] } \\
\text { observed }\end{array}$ & Volume \\
\hline $\begin{array}{c}\text { PanA-LVPRGS- } \\
\text { sfGFP-His } 6\end{array}$ & 34316.61 & 34316.52 & $40,880,260$ \\
\hline $\begin{array}{c}\text { GVLGNDAEGITLLPL } \\
\text { CFKPICIPTLPPLTGG } \\
\text { HA-LVPRGS-sfGFP- } \\
\text { His } 6 \text { + isopeptide bond }\end{array}$ & 31486.4 & 31487.53 & $83,891,928$ \\
\hline $\begin{array}{c}\text { GVLGNDAEGITLLPL } \\
\text { CFKPICIPTLPPLTGG } \\
\text { HA-LVPRGS-sfGFP- } \\
\text { His } 6 \text { + isopeptide bond } \\
+1 \text { disulfide bond }\end{array}$ & 31484.39 & 31485.59 & $130,032,300$ \\
\hline
\end{tabular}

Figure S12. Full length PanA-fusion proteins. (A) Sequence of PanA, A1, and sfGFP along with the SDS-PAGE gel analyzing Ni-NTA affinity purification of PanA-LVPRGS-A1-His 6 and PanA-LVPRGSGFP-His $_{6}$. FT: flowthrough, E1-E4: elutions. (B)-(C) LC-MS analysis of PanA-LVPRGS-A1-His 6 and PanA-LVPRGS-sfGFP-His 6 respectively. Tables of masses observed that correspond to fusion protein products. Volume refers to peak volume from TIC chromatogram. 
A

$$
\text { PanA } \triangle \text { C12-A1 sequence: }
$$

MNKAMATAKEVSELEALAAVDATHATRGVLGNDAEGITLLPLCFK PICSGDLENEVAQLEREVRSLEDEAAELEQKVSRLKNEIEDLKAEI GDLNNTSGIRRPAAKLNHHHHHH

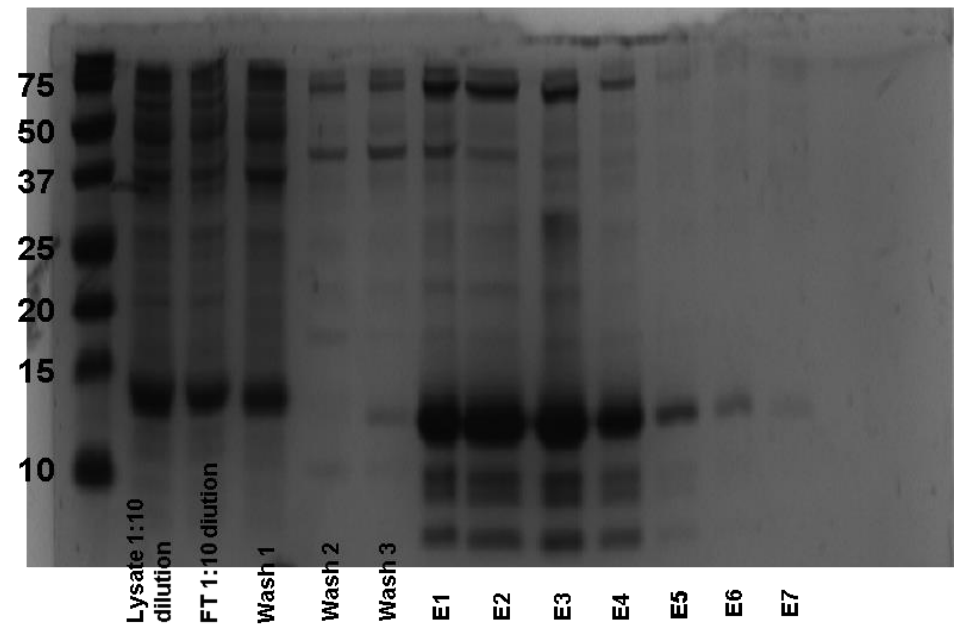

B

\begin{tabular}{|c|c|c|c|}
\hline Sequence & $\begin{array}{l}\text { Average } \\
\text { mass }[\mathrm{M}] \\
\text { expected }\end{array}$ & $\begin{array}{l}\text { Average } \\
\text { mass }[\mathrm{M}] \\
\text { detected }\end{array}$ & Volume \\
\hline $\begin{array}{c}\text { NKAMATAKEVSELEALA } \\
\text { AVDATHATR+PanA } \triangle \mathrm{C} 12 \\
+ \text { + A1+His-Tag } \\
+ \text { disulfide bond }\end{array}$ & 12362.71 & 12363.31 & 1505696 \\
\hline $\begin{array}{c}\text { PanA } \triangle \mathrm{C} 12+\mathrm{A} 1+\mathrm{His}-\mathrm{Tag} \\
\text { + disulfide bond }\end{array}$ & 9681.72 & 9681.87 & 1191060 \\
\hline $\begin{array}{c}\text { ATAKEVSELEALAAVDAT } \\
\text { HATR+PanA } \triangle \mathrm{C} 12+\mathrm{A} 1+\mathrm{Hi} \\
\text { sTag + disulfide bond }\end{array}$ & 11918.17 & 11917.92 & 968820 \\
\hline
\end{tabular}

Figure S13. PanA $\triangle C$ 12-A1 fusion protein. (A) Sequence of direct fusion protein and SDS-PAGE gel analyzing Ni-NTA affinity purification. FT: flowthrough, E1-E4: elutions (B) LC-MS analysis of the purified fusion protein. Table of masses observed that correspond to fusion protein products. In this table, PanA $\triangle \mathrm{C} 12$ refers to the core peptide sequence of PanA only. Note that although removal of the leader peptide was observed, no mass corresponding to isopeptide bond formation was observed. 
A

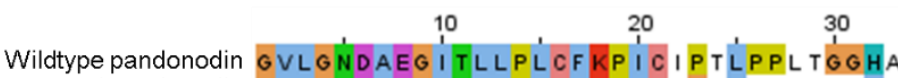

Tail-swapped pandonodin GVLGNDAEG I TLLPLCF KPI CSGDLENEVAQLE

B
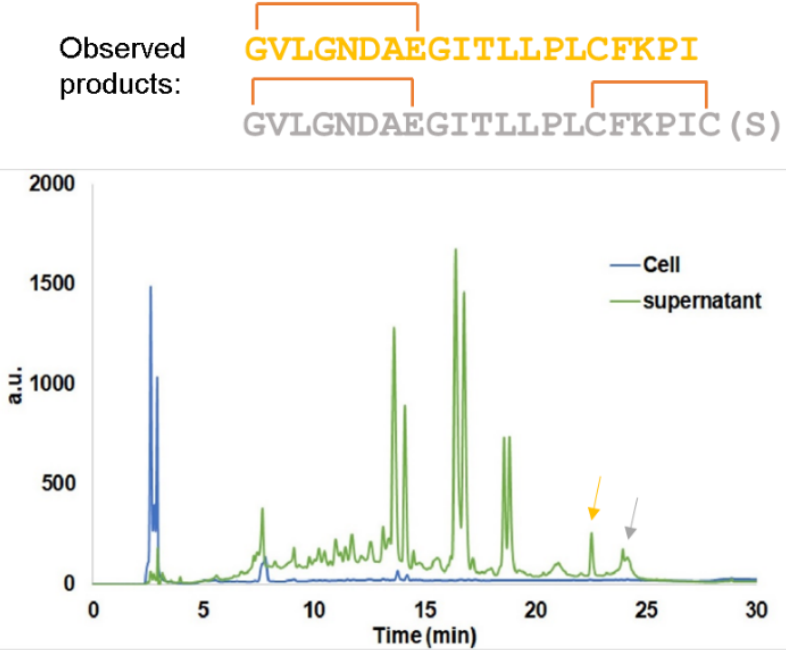

C

\begin{tabular}{|c|c|c|}
\hline $\begin{array}{c}\text { Sequence (with } \\
\text { isopeptide bond) }\end{array}$ & $\begin{array}{c}\text { Monoisotopic } \\
\text { mass [M] } \\
\text { predicted }\end{array}$ & $\begin{array}{c}\text { Monoisotopic } \\
\text { mass [M] } \\
\text { observed }\end{array}$ \\
\hline $\begin{array}{c}\text { PanA } \triangle \mathrm{C} 12-\mathrm{A} 1_{12}+\text { disulfide } \\
\text { bonded }\end{array}$ & 3438.71 & 3438.69 \\
\hline PanA $\Delta \mathrm{C} 12-\mathrm{A} 1_{12}$ & 3436.69 & 3436.69 \\
\hline PanA $\triangle \mathrm{C} 12-\mathrm{A} 1_{7}$ & 2898.41 & 2898.41 \\
\hline $\begin{array}{c}\text { PanA } \triangle \mathrm{C} 12-\mathrm{A} 1_{7} \\
+ \text { disulfide bonded }\end{array}$ & 2896.40 & 2896.40 \\
\hline PanA $\triangle \mathrm{C} 12-\mathrm{Ser}$ & 2241.15 & 2241.15 \\
\hline PanA $\Delta \mathrm{C} 12$ & 2154.12 & 2154.12 \\
\hline
\end{tabular}

\begin{tabular}{|c|c|c|}
\hline $\begin{array}{l}\text { Sequence (with } \\
\text { isopeptide bond) }\end{array}$ & $\begin{array}{l}\text { Monoisotopic } \\
\text { mass [M] } \\
\text { predicted }\end{array}$ & $\begin{array}{l}\text { Monoisotopic } \\
\text { mass [M] } \\
\text { observed }\end{array}$ \\
\hline $\operatorname{Pan} A \triangle C 13$ & 2051.11 & 2051.12 \\
\hline $\begin{array}{l}\text { PanA } \triangle C 12-S e r \\
+ \text { disulfide bond }\end{array}$ & 2239.14 & 2239.14 \\
\hline $\begin{aligned} & \text { PanA } \triangle \mathrm{C} 12 \\
+ & \text { disulfide bond }\end{aligned}$ & 2152.10 & 2152.11 \\
\hline
\end{tabular}

Figure S14. Replacement of last 12 aa of PanA with 12 aa of A1. (A) Sequence alignment of pandonodin peptide with the tail variant. (B) HPLC analysis of fusion peptide expression. Indicated peaks were collected and determined by LC-MS to be truncated sequences of the fusion peptide. (C) Table of masses of minor species observed in the cell extract and their corresponding sequences. (D) Table of masses of major species observed in the supernatant extract and their corresponding sequences. 


\section{Supplementary Tables}

Table S1. Chemical shift assignments for pandonodin.

\begin{tabular}{|c|c|c|c|c|c|c|c|c|}
\hline Residue & Hydrogen & Chemical Shift $\delta$ (ppm) & Residue & Hydrogen & Chemical Shift $\delta$ (ppm) & Residue & Hydrogen & Chemical Shift $\delta$ (ppm) \\
\hline GLY-1 & $\mathrm{H}$ & 7.580 & LEU-13 & $\mathrm{QB}$ & 0.988 & ILE-22 & QG2 & 0.951 \\
\hline GLY-1 & HA2 & 3.639 & LEU-13 & QD1 & 0.719 & PRO-23 & $\mathrm{HA}$ & 4.520 \\
\hline GLY-1 & HA3 & 4.508 & LEU-13 & QD2 & 0.924 & PRO-23 & HB2 & 1.975 \\
\hline VAL-2 & $\mathrm{H}$ & 8.379 & PRO-14 & $\mathrm{HA}$ & 4.765 & PRO-23 & HB3 & 2.226 \\
\hline VAL-2 & $\mathrm{HA}$ & 4.494 & PRO-14 & HB2 & 2.347 & PRO-23 & HD2 & 3.918 \\
\hline VAL-2 & $\mathrm{HB}$ & 2.329 & PRO-14 & HB3 & 2.038 & PRO-23 & HD3 & 3.642 \\
\hline VAL-2 & QG1 & 1.010 & PRO-14 & HD2 & 3.592 & PRO-23 & HG2 & 2.145 \\
\hline VAL-2 & QG2 & 0.962 & PRO-14 & HD3 & 3.693 & PRO-23 & HG3 & 1.992 \\
\hline LEU-3 & $\mathrm{H}$ & 7.333 & PRO-14 & HG2 & 2.071 & THR-24 & $\mathrm{H}$ & 7.846 \\
\hline LEU-3 & $\mathrm{HA}$ & 4.297 & PRO-14 & HG3 & 1.870 & TRR-24 & $\mathrm{HA}$ & 4.318 \\
\hline LEU-3 & $H G$ & 1.630 & LEU-15 & $\mathrm{H}$ & 7.275 & THR-24 & HB & 4.243 \\
\hline LEU-3 & QB & 1.636 & LEU-15 & $\mathrm{HA}$ & 4.640 & THR-24 & QG2 & 1.211 \\
\hline LEU-3 & QQD & 0.978 & LEU-15 & HG & 1.413 & LEU-25 & $\mathrm{H}$ & 7.936 \\
\hline GLY-4 & $\mathrm{H}$ & 7.371 & LEU-15 & $\mathrm{QB}$ & 1.596 & LEU-25 & $\mathrm{HA}$ & 4.703 \\
\hline GLY-4 & HA2 & 1.780 & LEU-15 & QD1 & 1.172 & LEU-25 & HB2 & 1.649 \\
\hline GLY-4 & $\mathrm{HA3}$ & 3.356 & LEU-15 & QD2 & 0.850 & LEU-25 & HB3 & 1.591 \\
\hline ASN-5 & $\mathrm{H}$ & 6.649 & CYS-16 & $\mathrm{H}$ & 8.623 & LEU-25 & HG & 1.816 \\
\hline ASN-5 & $\mathrm{HA}$ & 4.724 & CYS-16 & $\mathrm{HA}$ & 5.321 & LEU-25 & QQD & 0.960 \\
\hline ASN-5 & HB2 & 2.598 & CYS-16 & HB2 & 3.854 & PRO-26 & $\mathrm{HA}$ & 4.669 \\
\hline ASN-5 & HB3 & 3.057 & CYS-16 & HB3 & 3.506 & PRO-26 & HB2 & 2.275 \\
\hline ASN-5 & HD21 & 7.707 & PHE-17 & $\mathrm{H}$ & 8.871 & PRO-26 & HB3 & 1.993 \\
\hline ASN-5 & HD22 & 6.911 & PHE-17 & $\mathrm{HA}$ & 5.143 & PRO-26 & HD2 & 3.903 \\
\hline ASP-6 & $\mathrm{H}$ & 8.907 & PHE-17 & $\mathrm{HZ}$ & 7.149 & PRO-26 & HD3 & 3.642 \\
\hline ASP- 6 & $\mathrm{HA}$ & 5.143 & PHE-17 & QB & 3.053 & PRO-26 & $\mathrm{HG} 2$ & 2.105 \\
\hline ASP-6 & HB2 & 2.931 & PHE-17 & $\mathrm{QD}$ & 7.397 & PRO-26 & HG3 & 2.004 \\
\hline ASP- 6 & HB3 & 2.736 & PHE-17 & QE & 7.204 & PRO-27 & $\mathrm{HA}$ & 4.449 \\
\hline ALA-7 & $\mathrm{H}$ & 8.434 & LYS-18 & $\mathrm{H}$ & 8.623 & PRO-27 & HB2 & 1.977 \\
\hline ALA-7 & $\mathrm{HA}$ & 4.436 & LYS-18 & $\mathrm{HA}$ & 4.170 & PRO-27 & HB3 & 2.239 \\
\hline ALA-7 & $\mathrm{QB}$ & 1.369 & LYS-18 & HB2 & 1.785 & PRO-27 & HD2 & 3.799 \\
\hline GLU-8 & $\mathrm{H}$ & 8.055 & LYS-18 & HB3 & 1.699 & PRO-27 & HD3 & 3.652 \\
\hline GLU-8 & $\mathrm{HA}$ & 4.322 & LYS-18 & HG2 & 1.516 & PRO-27 & HG2 & 2.089 \\
\hline GLU-8 & HB2 & 1.533 & LYS-18 & HG3 & 1.465 & PRO-27 & HG3 & 2.022 \\
\hline GLU-8 & HB3 & 2.505 & LYS-18 & $\mathrm{QD}$ & 1.628 & LEU-28 & $\mathrm{H}$ & 8.271 \\
\hline GLU-8 & $\mathrm{HG} 2$ & 2.735 & LYS-18 & $\mathrm{QE}$ & 2.914 & LEU-28 & $\mathrm{HA}$ & 4.362 \\
\hline GLU-8 & HG3 & 2.444 & PRO-19 & $\mathrm{HA}$ & 4.572 & LEU-28 & HB2 & 1.754 \\
\hline GLY-9 & $\mathrm{H}$ & 8.286 & PRO-19 & HB2 & 2.109 & LEU-28 & HB3 & 1.655 \\
\hline GLY-9 & HA2 & 4.018 & PRO-19 & HB3 & 2.621 & LEU-28 & HG & 0.980 \\
\hline GLY-9 & HA3 & 3.657 & PRO-19 & HD2 & 3.513 & LEU-28 & QQD & 0.937 \\
\hline ILE-10 & $\mathrm{H}$ & 6.818 & PRO-19 & HD3 & 3.602 & THR-29 & $\mathrm{H}$ & 7.781 \\
\hline ILE-10 & $\mathrm{HA}$ & 4.453 & PRO-19 & HG2 & 1.698 & THR-29 & $\mathrm{HA}$ & 4.300 \\
\hline ILE-10 & $\mathrm{HB}$ & 1.975 & PRO-19 & HG3 & 2.037 & THR-29 & HB & 4.281 \\
\hline ILE-10 & HG12 & 1.555 & ILE-20 & $\mathrm{H}$ & 9.337 & TRR-29 & QG2 & 1.207 \\
\hline ILE-10 & HG13 & 1.094 & ILE-20 & $\mathrm{HA}$ & 4.175 & GLY-30 & $\mathrm{H}$ & 8.392 \\
\hline ILE-10 & OD1 & 0.895 & ILE-20 & $\mathrm{HB}$ & 2.466 & GLY-30 & HA2 & 3.917 \\
\hline ILE-10 & QG2 & 0.986 & ILE-20 & HG12 & 1.304 & GLY-30 & HA3 & 3.892 \\
\hline THR-11 & $\mathrm{H}$ & 8.592 & ILE-20 & HG13 & 1.593 & GLY-31 & $\mathrm{H}$ & 8.344 \\
\hline THR-11 & $\mathrm{HA}$ & 4.017 & ILE-20 & QD1 & 0.917 & GLY-31 & HA2 & 3.871 \\
\hline THR-11 & $\mathrm{HB}$ & 3.679 & ILE-20 & QG2 & 1.090 & \begin{tabular}{|l|} 
GLY-31 \\
\end{tabular} & HA3 & 3.828 \\
\hline THR-11 & QG2 & 1.238 & CYS-21 & $\mathrm{H}$ & 7.607 & HIS-32 & $\mathrm{H}$ & 7.995 \\
\hline LEU 12 & $\mathrm{H}$ & 7.549 & CYS-21 & $\mathrm{HA}$ & 5.031 & HIS-32 & $\mathrm{HA}$ & 4.743 \\
\hline LEU-12 & $\mathrm{HA}$ & 4.211 & CYS-21 & HB2 & 3.085 & HIS-32 & HB2 & 3.319 \\
\hline LEU-12 & $\mathrm{HG}$ & 1.686 & CYS-21 & HB3 & 2.950 & HIS-32 & HB3 & 3.179 \\
\hline LEU-12 & $\mathrm{QB}$ & 1.164 & ILE-22 & $\mathrm{H}$ & 9.373 & HIS-32 & HD2 & 7.403 \\
\hline LEU-12 & QD1 & 0.974 & ILE-22 & $\mathrm{HA}$ & 4.122 & HIS-32 & HE1 & 8.775 \\
\hline LEU-12 & $\mathrm{QD} 2$ & 0.916 & ILE-22 & $\mathrm{HB}$ & 1.680 & ALA-33 & $\mathrm{H}$ & 8.428 \\
\hline LEU-13 & $\mathrm{H}$ & 7.545 & ILE-22 & $\mathrm{HG} 12$ & 1.765 & ALA-33 & $\mathrm{HA}$ & 4.397 \\
\hline LEU-13 & $\mathrm{HA}$ & 5.358 & ILE-22 & HG13 & 1.156 & ALA-33 & QB & 1.439 \\
\hline LEU-13 & $\mathrm{HG}$ & 1.250 & ILE-22 & OD1 & 0.888 & & & \\
\hline
\end{tabular}


Table S2. Statistics for pandonodin structural calculations.

\begin{tabular}{l|l}
\hline Constraints & Constraint Violations \\
\hline Total $=466$ & Distance violations, $>0.5 \AA: 0$ \\
\hline Distance, $\mathrm{i}=\mathrm{j}: 125$ & RMS deviations: $0.014 \AA$ \\
\hline Distance, $|\mathrm{i}-\mathrm{j}|=1: 188$ & $\begin{array}{l}\text { Average backbone RMSD to } \\
\text { mean: } 2.60 \AA\end{array}$ \\
\hline Distance, $|\mathrm{i}-\mathrm{j}|>1: 153$ & $\begin{array}{l}\text { Average heavy atom RMSD to } \\
\text { mean: } 2.86 \AA\end{array}$
\end{tabular}

Table S3: NOEs between lock and ring residues:

\begin{tabular}{|c|c|c|c|c|c|c|}
\hline Position & Residue & Hydrogen & Position & Residue & Hydrogen & Distance $(\AA)$ \\
\hline 15 & LEU & QD1 & 1 & GLY & H & 3.2 \\
\hline 15 & LEU & HA & 1 & GLY & HA2 & 3.34 \\
\hline 15 & LEU & QD2 & 1 & GLY & HA2 & 3.47 \\
\hline 15 & LEU & QB & 1 & GLY & HA2 & 3.65 \\
\hline 15 & LEU & QD1 & 1 & GLY & HA2 & 3.82 \\
\hline 15 & LEU & QB & 1 & GLY & H & 3.89 \\
\hline 15 & LEU & QD2 & 1 & GLY & HA3 & 3.92 \\
\hline 15 & LEU & QB & 8 & GLU & HG2 & 4 \\
\hline 16 & CYS & HA & 4 & GLY & HA3 & 3.97 \\
\hline 17 & PHE & QE & 4 & GLY & HA2 & 3.74 \\
\hline 17 & PHE & QE & 3 & LEU & QQD & 3.9 \\
\hline 18 & PHE & QD & 4 & GLY & HA3 & 3.96 \\
\hline 18 & LYS & H & 6 & ASP & H & 3.23 \\
\hline 18 & LYS & QB & 6 & ASP & QB & 3.45 \\
\hline 18 & LYS & H & 6 & ASP & HB2 & 3.93 \\
\hline 18 & LYS & H & 6 & ASP & HB3 & 3.93 \\
\hline
\end{tabular}


Table S4. Primers and constructs used in this study.

\begin{tabular}{|c|c|c|c|c|}
\hline Primer Name & Primer Sequence & Primer Descriptiion & \begin{tabular}{|l|} 
Plasmid \\
construct
\end{tabular} & Plasmid Description \\
\hline panABCD For & $\begin{array}{l}\text { TTACCTCTAGATTCCGTT } \\
\text { CGTGCCCATGACAT }\end{array}$ & For primer for amplifying panABCD & pWC100 & panABCD pASK75 \\
\hline panABCD Rev & $\begin{array}{l}\text { TTAGAAGCTTGAACCAAG } \\
\text { CGCGTTAGCCAAG }\end{array}$ & Rev primer used amplifying pan $A B C D$ & pWC100 & panABCD pASK75 \\
\hline panABCD Seq F1 & $\begin{array}{l}\text { ACTCGGCTTCGACGCAT } \\
\text { G }\end{array}$ & Sequencing primer & pWC100/pWC102 & \\
\hline panABCD Seq F2 & $\begin{array}{l}\text { CTGCTGGCCTGGTACAT } \\
\text { CA }\end{array}$ & Sequencing primer & pWC100/pWC102 & \\
\hline panABCD Seq F3 & $\begin{array}{l}\text { GAGCGGCTGGATATCGA } \\
\text { CTG }\end{array}$ & Sequencing primer & pWC100/pWC102 & \\
\hline panABCD Seq F4 & $\begin{array}{l}\text { AATCTCTGGCGGCGTGA } \\
\text { CAA }\end{array}$ & Sequencing primer & pWC100/pWC102 & \\
\hline panABCD Seq F5 & $\begin{array}{l}\text { GTCTGGTGTTCGGGTTG } \\
\text { CT }\end{array}$ & Sequencing primer & pWC100/pWC102 & \\
\hline EcoRI Kpnl panA For & $\begin{array}{l}\text { GATAGCGAATTCGGTACC } \\
\text { ATTAAAGAGGAGAAATTAA } \\
\text { CCATGAATAAGGCAATGG } \\
\text { CAACT }\end{array}$ & For primer for amplifying pan $A$ & $\begin{array}{l}\text { pWC101/pWC103- } \\
\text { 110/pLC01-02 }\end{array}$ & \\
\hline panA HindIII Rev & $\begin{array}{l}\text { AATATAAGCTTCGGACAC } \\
\text { CTCAGGCATGG }\end{array}$ & Rev primer for amplifying panA & pWC101 & panA pQE-80 \\
\hline $\begin{array}{l}\text { mcjBCD promoter Nhel } \\
\text { For }\end{array}$ & $\begin{array}{l}\text { GAATCCAAGCTAGCCATC } \\
\text { AATTAAG }\end{array}$ & For primer for amplifying $m c j B C D$ & pWC102 & panA panBCD $\mathrm{p}$ \\
\hline $\begin{array}{l}\text { mcjBCD promoter RBS } \\
\text { Rev }\end{array}$ & $\begin{array}{l}\text { TTTTGCACACTCCCTCCT } \\
\text { GTAG }\end{array}$ & Rev primer for amplifying $m c j B C D$ promoter & pWC102 & panA panBCD pQE-80 \\
\hline RBS panB For & $\begin{array}{l}\text { CTACAGGAGGGAGTGTG } \\
\text { CAAAATGCCTGAGGTGTC } \\
\text { CGACCCGAC }\end{array}$ & For primer for amplifying pan $B C D$ & pWC102 & panA panBCD pQE-80 \\
\hline panBCD Nhel Rev & $\begin{array}{l}\text { GATAAGCTAGCGAACCAA } \\
\text { GCGCGTTAGCCAAG }\end{array}$ & Rev primer for & pWC102 & panA panBCD pQE-80 \\
\hline panA delC4 HindllI Rev & $\begin{array}{l}\text { AATATAAGCTTCAGGTCA } \\
\text { GCGGCGGCAACGT }\end{array}$ & Rev primer for cloning panA trunc & pWC103 & $\begin{array}{l}\text { panA } \triangle \mathrm{C} 4 \text { panBCD pQE- } \\
80\end{array}$ \\
\hline panA delC8 HIndIII Rev & $\begin{array}{l}\text { AATATAAGCTTCACAACG } \\
\text { TGGGAATGCAGATCGG }\end{array}$ & Rev primer for cloning panA truncation & pWC104 & $\begin{array}{l}\text { panA } \triangle \mathrm{C} 8 \text { panBCD pQE- } \\
80\end{array}$ \\
\hline panA delC12 HindllI Rev & $\begin{array}{l}\text { AATATAAGCTTCAGCAGA } \\
\text { TCGGCTTGAAGCACAG }\end{array}$ & Rev primer for cloning panA truncation & pWC105 & $\begin{array}{l}\text { panA } \triangle \mathrm{C} 12 \text { panBCD pQE- } \\
80\end{array}$ \\
\hline panA delC14 HindIII Rev & $\begin{array}{l}\text { AATATAAGCTTCACGGCT } \\
\text { TGAAGCACAGCGGCA }\end{array}$ & Rev primer for cloning panA truncation & pWC106 & $\begin{array}{l}\text { panA } \triangle \mathrm{C} 14 \text { panBCD pQE- } \\
80\end{array}$ \\
\hline panA delC16 HindIIII Rev & $\begin{array}{l}\text { AATATAAGCTTCAGAAGC } \\
\text { ACAGCGGCAGGAG }\end{array}$ & Rev primer for cloning panA truncation & pWC109 & $\begin{array}{l}\text { panA } \triangle \mathrm{C} 16 \text { panBCD pQE- } \\
80\end{array}$ \\
\hline panA delC17 HindIIII Rev & $\begin{array}{l}\text { AATATAAGCTTCAGCACA } \\
\text { GCGGCAGGAGCGT }\end{array}$ & Rev primer for $\mathrm{C}$ & pWC110 & $\begin{array}{l}\text { panA } \triangle \mathrm{C} 17 \text { panBCD pQE- } \\
80\end{array}$ \\
\hline panA thrombin For & $\begin{array}{l}\text { CCATGCCCTGGTTCCGC } \\
\text { GTGGATCT }\end{array}$ & $\begin{array}{l}\text { For primer for amplifying genes for A1 or } \\
\text { sfGFP }\end{array}$ & pWC107/pWC108 & \\
\hline A1 HindIIII Rev & $\begin{array}{l}\text { TAGTAAAGCTTCAGTGAT } \\
\text { GGTGATGGTGATGATTCA } \\
\text { GCTTGG }\end{array}$ & Rev primer for amplifying gene for A1 & pWC107 & $\begin{array}{l}\text { panA-LVPRGS-A1-His } \\
\text { panBCD pQE- } 80\end{array}$ \\
\hline panA thrombin Rev & $\begin{array}{l}\text { ACGCGGAACCAGGGCAT } \\
\text { GGCCCCCGGTCA }\end{array}$ & Rev primer for amplifying panA & pWC107/pWC108 & \\
\hline sfGFP Hindlll Rev & $\begin{array}{l}\text { TAGTAAAGCTTCAGTGAT } \\
\text { GGTGATGGTGATGTTTG } \\
\end{array}$ & Rev primer for amplifying gene for sfGFP & pWC108 & $\begin{array}{l}\text { panA-LVPRGS-sfGFP-His } \\
\text { panBCD pQE-80 }\end{array}$ \\
\hline panA_delC12_A1-For & $\begin{array}{l}\text { GCTTCAAGCCGATCTGCA } \\
\text { GCGGTGACCTGGAAAAC } \\
\text { GAAG }\end{array}$ & For primer for amplifying gene for $\mathrm{A} 1$ & pLC01/pLC02 & \\
\hline A1 N12 Hindlll Rev & $\begin{array}{l}\text { AACGTAAGCTTTCATTCC } \\
\text { AGCTGGGCCACTTC }\end{array}$ & $\begin{array}{l}\text { Rev primer for amplifying gene for truncated } \\
\text { A1 }\end{array}$ & pLC01 & $\begin{array}{l}\text { panA } \triangle \mathrm{C} 12-\mathrm{A} 1(\mathrm{~N} 12) \\
\operatorname{pan} B C D \text { pQE-80 }\end{array}$ \\
\hline panA_delC12_A1_Rev & $\begin{array}{l}\text { CCAGGTCACCGCTGCAG } \\
\text { ATCGGCTTGAAGCACAG }\end{array}$ & Rev primer for amplifying pan $A \mathrm{C} 12$ & pLC02 & $\begin{array}{l}\text { panA } \triangle \mathrm{C} 12-\mathrm{A} 1-\mathrm{His} \\
\text { pan } B C D \text { pQE-80 }\end{array}$ \\
\hline $\begin{array}{l}\text { panA C16A C21A } \\
\text { forward }\end{array}$ & $\begin{array}{l}\text { TGCCGCTGGCGTTCAAG } \\
\text { CCGATCGCGATTCCC }\end{array}$ & $\begin{array}{l}\text { For primer for cloning panA C16A C21A } \\
\text { variant }\end{array}$ & pLC19 & $\begin{array}{l}\text { panA C16A C21A panBCD } \\
\text { pQE-80 }\end{array}$ \\
\hline $\begin{array}{l}\text { panA C16A C21A } \\
\text { reverse }\end{array}$ & $\begin{array}{l}\text { GGGAATCGCGATCGGCT } \\
\text { TGAACGCCAGCGGCA } \\
\end{array}$ & $\begin{array}{l}\text { Rev primer for cloning panA C16A C21A } \\
\text { variant }\end{array}$ & pLC19 & $\begin{array}{l}\text { panA C16A C21A panBCD } \\
\text { pQE-80 }\end{array}$ \\
\hline $\begin{array}{l}\text { panA mutant Kpnl } \\
\text { forward }\end{array}$ & $\begin{array}{l}\text { ATTCGGTACCATTAAAGA } \\
\text { GGAGAAATTAAC }\end{array}$ & For primer for amplifying panA & pLC19 & $\begin{array}{l}\text { panA C16A C21A panBCD } \\
\text { pQE-80 }\end{array}$ \\
\hline $\begin{array}{l}\text { panA mutant Nhel } \\
\text { reverse }\end{array}$ & $\begin{array}{l}\text { TGCTGCTAGCTTGGATT } \\
\text { CTCACCAATAAA }\end{array}$ & Rev primer for amplifying panA & pLC19 & $\begin{array}{l}\text { panA C16A C21A panBCD } \\
\text { pQE-80 }\end{array}$ \\
\hline
\end{tabular}

